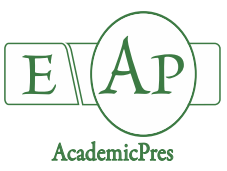

Younes KM et al. (2021)

Notulae Botanicae Horti Agrobotanici Cluj-Napoca

Volume 49, Issue 1, Article number 12293

DOI: $10.15835 /$ nbha 49112293

Research Article

\title{
In-vitro evaluation of antioxidant and antiradical potential of successive extracts, semi-purified fractions and biosynthesized silver nanoparticles of Rumex vesicarius
}

\author{
Kareem M. YOUNES ${ }^{1,2}$, Ramy M. ROMEILAH ${ }^{3,5}$, Hossam S. EL- \\ BELTAGI $^{4,5 *}$, Hani EL MOLL ${ }^{3}$, Saravanan RAJENDRASOZHAN ${ }^{3}$, \\ Hany A. EL-SHEMY', Emad A. SHALABY ${ }^{5}$ \\ ${ }^{1}$ Hail University, College of Pharmacy, Department of Pharmaceutical Chemistry, Hail, Saudi Arabia; k.younes@uoh.edu.sa \\ ${ }^{2}$ Cairo University, Faculty of Pharmacy, Department of Analytical Chemistry, Cairo, Egypt \\ ${ }^{3}$ Hail University, College of Science, Department of Chemistry, Hail, Saudi Arabia; \\ r.romeilah@uoh.edu.sa; h.elmoll@uoh.edu.sa; s.rajendrasozhan@uoh.edu.sa \\ ${ }^{4}$ King Faisal University, College of Agriculture and Food Science, Agricultural Biotechnology Department, P.O. Box 420, Al-Ahsa, \\ 31982, Saudi Arabia; helbeltagi@kfu.edu.sa (*corresponding author) \\ ${ }^{5}$ Cairo University, Faculty of Agriculture, Department of Biochemistry, Giza, 12613, \\ Egypt;dremad2009@yahoo.com; helshemy@hotmail.com
}

\begin{abstract}
The aim of the present study was to assess in vitro the antiradical and antioxidant activities of successive extracts and semi-purified fractions from Rumex vesicarius $\mathrm{L}$. In the present work, three extracts (n-Hexane, ethyl acetate and methanol) and 22 column fractions of methanolic extract (as promising extract) were evaluated against 2,2-diphenyl- 1-picrylhydrazyl (DPPH•) and 2,2-azinobis (3-ethylbenzothiazoline- 6sulfonic acid) (ABTS) radical scavenging methods as antiradical and antioxidant activities compared with Butylated hydroxytoluene (BHT) as synthetic standard and silver nanoparticles of methanolic extract (Ag$\mathrm{NPs}-\mathrm{Me}$ ), in addition to analysis of chemical constituents of extract and fraction using Gas chromatographymass spectrometry (GC-MS). The obtained results revealed that, both methods go parallel showing that the concentration of extract and incubation time are dependent and proportional with phenolic compounds concentration. Absolute methanol extract recorded the highest antioxidant activity when compared with the other crude extracts with 79.3 and $78.8 \%$ against DPPH and ABTS respectively when compared with BHT as synthetic standard (89.4 and 89.9\%) against DPPH and ABTS respectively. Calculation of the antiradical activity units showed the highest values of methanolic extract and its promising fraction (No. 12) after 300 seconds ( 5 minutes) comparing with antioxidant activity $(30 \mathrm{~min})$. Also, the antioxidant activity increased with synthetic Ag-NPs-Me when compared with methanolic extract by (IC50 $=53.9$ and $74.6 \mu \mathrm{g} / \mathrm{ml}$ respectively). Thus, the GC-MS analysis of successive extracts of $R$. vesicarius $L$ showed a highly complex profile, containing approximately 24 different components. One pure compound was identified from fraction No. 12 . The identified compound was l-(+)-ascorbic acid 2, 6-dihexadecanoate. The data also revealed presence of closely similar antioxidant activities in methanolic extract or its pure compounds with BHT when mixed at different proportions. From the obtained results it could be concluded that $R$. vesicarius methanolic extracts and
\end{abstract}

Received: 20 Feb 2021. Received in revised form: 02 Mar 2021. Accepted: 09 Mar 2021. Published online: 15 Mar 2021.

From Volume 49, Issue 1, 2021, Notulae Botanicae Horti Agrobotanici Cluj-Napoca journal will use article numbers in place of the traditional method of continuous pagination through the volume. The journal will continue to appear quarterly, as before, with four annual numbers. 
fractions can be extensively used in the production of potential antioxidant, antiradical and AgNPs-Me for biomedical application on the consumer's health.

Keywords: biological activities; chemical constituents; Rumex vesicarius; silver nanoparticles; successive extracts

\section{Introduction}

Rumex vesicarius L. is a wild edible plant, known in Arabic as Humeidh and in English as Bladder dock, possible eaten fresh or in cooked form and can be used in the daily diet. It is distributed in many parts of Middle East regions especially Kingdom of Saudi Arabia and semi-desert areas of North Africa. In Hail region, KSA, $R$. vesicarius $\mathrm{L}$. is antioxidant source and widely used as food and as a medicinal herb (Farooq et al., 2020).

Various highly active free radicals are responsible for human disease (e.g: ageing, cancer, inflammation, etc) and food deterioration could be delayed by the use of antioxidants compounds present in different Rumex species. The phytochemicals of crude organic extracts of $R$. vesicarius $\mathrm{L}$. was analysed and identified using GCMS by Farooq et al. (2020) who found that thirty-five active compounds were identified in the stem extract of Rumex sp. From the major compounds present are propanoic acid, 2- [(trimethylsilyl)oxy]-, trimethylsilyl ester, butane, 1,2,3-tris(trimethylsiloxy), and butanedioic acid, bis (trimethylsilyl) ester. The biological activities of $R$. vesicarius L. crude extracts were evaluated by (Al-Abd et al., 2017; Shalaby and Hameed, 2020; Farooq et al., 2020) they reported that the crude extracts possess antioxidant activity against DPPH and ABTS radical assay in addition to anticancer activity against human breast cancer (MCF7), human colon carcinoma (Lovo, and Caco-2), human hepatocellular carcinoma (HepG2) cell lines. Most of the crude extracts did not show any significant toxicity.

The radical scavenging (antioxidant) activity of $R$. vesicarius was studied by $\mathrm{Al}$ Aboody (2015) who revealed that the maximum percentage of DPPH inhibition was exhibited by ethyl acetate followed by distilled water extract and the lowest activity was recorded by hexane extract with concentration $1000 \mathrm{ppm}$. This investigation supports the folkloric uses of the Rumex species with different biological activities such as antioxidant, anticancer and anti-inflammatory.

There is a great variation between two expression "antiradical" and "antioxidant" activity as recorded by Shalaby and Shanab (2013) and according to Tirzitis and Bartosz (2010) the antiradical activity characterizes the ability of active ingredients or chemical compounds to react with different types of free radicals. However, antioxidant activity reflects the ability of active ingredients or chemical compounds to inhibit the steps or the process of oxidation reaction. Moreover, all test methods using a stable free radical (such as, ABTS or DPPH) give information on the antioxidant or antiradical activity (El-Beltagi et al., 2018; 2019a, b; Gaber et al., 2021).

The whole plant in addition to its extracts are currently used in silver nanoparticles preparation, because of their contents from bioactive compounds especially reducing agent compounds such as phenolic compounds, amines, sugars, vitamins ---etc. Several biological activities such as cytotoxicity, antimicrobial, antioxidant and anticancer of the biosynthesized nanoparticles have been reported (Mohamed et al., 2009; Huo et al., 2018; Jin et al., 2018; Lakshmanan et al., 2018; Chahardoli et al., 2018; Khattak et al., 2019; ElBeltagi et al., 2020a, b; Dawi et al., 2021). Moreover, Adewale et al. (2020) revealed the green plants contain a wide variety of natural products that could serve as reducing and capping/stabilizing agent in biosynthesis of silver nanoparticles (SNPs). These active compounds also enhance the antioxidant activity of the synthesized nanoparticles based on the results of in vitro antioxidant methods performed.

The synergism effect of methanolic plant extract as antioxidant was determined by Aboul-Enein et al. (2014) who reported the synergistic action of a wide spectrum of antioxidants may be more effective than the activity a single antioxidant. 
The present work was designed to investigate the phytochemical contents of $R$. vesicarius plant and evaluate the activity of its successive extracts as an antioxidant and antiradical and to compare the results with silver nanoparticles prepared from its methanolic extract.

\section{Materials and Methods}

\section{Chemicals and reagents}

Pure hexane, chloroform, ethanol, ethyl acetate, ethanol and methanol were purchased from E. Merck Co. (Darmstadt, Germany). Sulfarhodamine, 2, 2 diphenyl-1-picrylhydrazyl (DPPH), 2, 2'- azino-bis (ethylbenzthiazoline-6-sulfonic acid (ABTS+) were purchased from Sigma-Aldrich (St. Louis, MO, USA). Gallic acid and butylated hydroxyl toluene (BHT), purchased from Sigma-Aldrich (St. Louis, MO, USA).

\section{Collection of plant materials}

$R$. vesicarius L. plant was collected from the desert of Hail region, KSA during February month 2020. The collected plant samples were kindly identified by the Botany Department, Faculty of Science, Cairo University, Giza, Egypt. The following is the taxonomy or classification of the plant under study

Class: Dicotyledons

Order: Polygonales

Family: Polygonaceae

Genus: Rumex

Species: vesicarius $\mathrm{L}$.

\section{Plant extraction}

The collected plant was air-dried and then grinded to fine powder. The dried powder $(100 \mathrm{~g})$ was subjected to extraction with successive selective solvents according to Rosenthaler (1930). Hexane, ethyl acetate, and methanol were used. The polarity was increased from non-polar to highly polar, the extraction process was repeated three times. The organic solvent extract was combined and concentrated under vacuum at $40{ }^{\circ} \mathrm{C}$ to obtain a dry crude extract for each solvent used.

\section{Fractionation of methanolic plant extract as promising extract}

The chromatographic column ( $40 \mathrm{~cm}$ length, $2.5 \mathrm{~cm}$ diameter) was packed with $150 \mathrm{~g}$ silica gel (60-120 mesh for column chromatography) using hexane as solvent. $5.0 \mathrm{~g}$ of methanol crude extract of $R$. vesicarius $\mathrm{L}$. (as promising crud extract) were grounded very well with silica gel powder and then placed on the top of the packed column. The column was then sequentially eluted with $100 \%$ hexane and increased the polarity with chloroform followed by ethyl acetate and ethanol solvent (Table 1), the polarity increased by $15 \%$ between each mobile phase mixtures (total 21 fractions were obtained) as the following:

Table 1. Fractions collected from successive extracts of Rumex vesicarius

\begin{tabular}{|c|c|c|c|c|c|c|c|c|}
\hline \multirow{2}{*}{$\begin{array}{c}\text { Solvent/ } \\
\text { Sample no. }\end{array}$} & \multicolumn{9}{|c|}{ Fractions No. } \\
\cline { 2 - 10 } & 1 & 2 & 3 & 4 & 5 & 6 & 7 & 8 \\
\hline Hexane & 100 & 85 & 70 & 55 & 40 & 25 & 10 & 0 \\
\hline Chloroform & 0 & 15 & 30 & 45 & 60 & 75 & 90 & 100 \\
\hline Sample no. & 9 & 10 & 11 & 12 & 13 & 14 & 15 & 16 \\
\hline Chloroform & 85 & 70 & 55 & 40 & 25 & 10 & 0 & \\
\hline Ethyl acetate & 15 & 30 & 45 & 60 & 75 & 90 & 100 & \\
\hline Sample no. & 17 & 18 & 19 & 20 & 21 & 22 & & \\
\hline Ethyl acetate & 85 & 70 & 55 & 40 & 25 & 10 & 0 & \\
\hline Ethanol & 15 & 30 & 45 & 60 & 75 & 90 & 100 & \\
\hline
\end{tabular}




\section{Qualitative phytochemical screening}

Qualitative phytochemical analysis of $R$. vesicarius $\mathrm{L}$. extracts were done by following the method described by Harborne (1973) and Trease and Evans (1983).

\section{DPPH radical scavenging activity}

The scavenging effects of $R$. vesicarius $\mathrm{L}$. extracts and fractions were determined by the method of Yen and Chen (1995), where, $2.0 \mathrm{ml}$ of $0.16 \mathrm{mM}$ DPPH solution (in methanol) was added to a test tube containing $1.0 \mathrm{~mL}$ aliquot of sample (extracts, fractions and Ag-Nps-Me) at 100 and $200 \mu \mathrm{g} \mathrm{ml}^{-1}$. The mixture was vortexed for $1 \mathrm{~min}$ and kept at room temperature for $30 \mathrm{~min}$. in the dark. The absorbance of all the sample solutions and BHT as synthetic standard were measured at $517 \mathrm{~nm}$. The percentage (\%) of scavenging activity was calculated as the following:

$\%$ Antioxidant activity $=($ Control-Sample $x$ 100 $) /$ Control

Where: control in DPPH solution $(0.16 \mathrm{mM})$.

\section{ABTS radical cation scavenging assay}

This assay was based on the ability of different substances to scavenge [2, 2'- azino-bis ethylbenzthiazoline-6-sulfonic acid $\left(\mathrm{ABTS}^{+}\right)$] radical cation in comparison to a standard (BHT). The radical cation was prepared by mixing $7 \mathrm{mM}$ ABTS stock solution with $2.45 \mathrm{mM}$ potassium persulfate $(1 / 1, \mathrm{v} / \mathrm{v})$ and leaving the mixture for 4-16 hrs. until the reaction was completed and the absorbance was stable. The (ABTS $\left.{ }^{+}\right)$ solution was diluted with ethanol until it gives an absorbance of $0.700 \pm 0.05$ at $734 \mathrm{~nm}$ for measurements according to Re et al. (1999). The photometric Assay was conducted on $0.9 \mathrm{~mL}$ of (ABTS+). and $0.1 \mathrm{~mL}$ of tested samples at 100 and $200 \mu \mathrm{g} \mathrm{ml}^{-1}$, mixed for $45 \mathrm{~s}$, and the measurements were taken at $734 \mathrm{~nm}$ after $1 \mathrm{~min}$. The antioxidant activity of the tested samples was calculated by determining the decrease in absorbance at different concentrations by using the following equation:

$\mathrm{E}=((\mathrm{Ac}-\mathrm{At}) / \mathrm{Ac}) \mathrm{x} 100$, where: At and Ac are the respective absorbance of tested samples and $\mathrm{ABTS}^{+}$

\section{Determination of total phenolic content}

The total phenolic contents of methanolic extract as a promising antioxidant and RV-SNPs was determined by the Folin-Ciocalteu method (Wen et al., 2010). Briefly, $0.25 \mathrm{~mL}$ of each extract was mixed with $1.25 \mathrm{~mL}$ of $1 \mathrm{~N}$ Folin-Ciocalteu reagent. After $5 \mathrm{~min}, 1 \mathrm{~mL}$ of sodium carbonate aqueous solution $(7.5 \%$, w/v) was added to the mixture and completed the reaction for $120 \mathrm{~min}$ at room temperature. The absorbance was measured at $765 \mathrm{~nm}$ using a UV-visible spectrophotometer (Shimadzu UV-1800, Japan). The results were expressed in equivalent milligrams of gallic acid per gram of dry weight of plant extract ( $\left.\mathrm{mg} \mathrm{GAE} \mathrm{g}^{-1} \mathrm{DW}\right)$.

\section{Measurement of antiradical activity of promising extract and fraction}

DPPH• and ABTS radicals in its radical form have characteristic absorbance at 517 and $734 \mathrm{~nm}$ respectively, which disappears after its reduction by an antiradical compound. The reduction of DPPH and ABTS can thus be monitored by measuring the decrease in its absorbance at 517 and $734 \mathrm{~nm}$ when react with plant extracts or its fractions during the reaction time $(30-300 \mathrm{sec})$ at $100 \mathrm{\mu gml}^{-1}$. All details related to the method are described by Shalaby and Shanab (2013). The antiradical activity (AU515) was calculated according to the equation:

AU515 $=($ A0-A1 $)-($ A0K-A1K $)$

where AU515 is the antiradical activity of the extract, A0K the absorbance of the control sample at the beginning of the reaction, and $\mathrm{A} 1 \mathrm{~K}$ the absorbance of the control sample after incubation times $(30-300 \mathrm{sec})$ of the reaction. Because $\mathrm{A} 0 \mathrm{~K}-\mathrm{A} 1 \mathrm{~K}$ was always equal to 0 , the above equation was simplified to: $\mathrm{AU} 515=\mathrm{A} 0-$ A1 


\section{Gas-chromatographic analysis}

GC-MS analysis was performed to identify and quantify active ingredients extracted from Rumex vesicarius $\mathrm{L}$. extracts. The analysis was carried out using Trace GC1300-TSQ mass spectrometer from Thermo Scientific, Austin, TX, USA using He at $1 \mathrm{ml} / \mathrm{min}$ as carrier gas. An TG-5MS capillary column $(30 \mathrm{~m} \times 0.25$ $\mathrm{mm} \times 0.25 \mu \mathrm{m}$ film thickness) was used. The oven temperature was programmed as follow: initial temperature of $60^{\circ} \mathrm{C}$ was kept for $1 \mathrm{~min}$. and temperature was then increased, at rate of $5.0^{\circ} \mathrm{C} / \mathrm{min}$ to $200^{\circ} \mathrm{C}$ and maintain for $2 \mathrm{~min}$ at this temperature. Injector temperature was $260^{\circ} \mathrm{C}$, and injections were made in the split mode with a split flow $1: 25$. Mass spectrometer was operating as follow: ion source temperature $250^{\circ} \mathrm{C}$, ionization energy $70 \mathrm{eV}$ (electron impact ionization), $\mathrm{m} / \mathrm{z}$ scanning range 50-650 Da. The acquisition of chromatographic data was performed by means of WILEY 09 and NIST 11 mass spectral database.

\section{Thin layer chromatography (TLC)}

The separation of active compounds from the promising fraction of Rumex vesicarius $\mathrm{L}$ (Fraction No. 12) was performed using Precoated silica gel plates (TLC F254) with using Benzene: acetone $(9: 1 \mathrm{v} / \mathrm{v})$ as a mobile phase and the separated spot was scratched. Two dimensions TLC that was done for this spot confirmed presence of a pure compound. GC-MS analysis with the same previous conditions was performed to identify and quantify the separated active compound (El-fayoumy et al., 2021).

\section{Bio-autography for antioxidant activity}

A rapid TLC screening method for antioxidant activity was done using the 2, 2-diphenyl-1-picryl hydrazyl radical (DPPH) as a spray reagent. TLC was performed for all $R$. vesicarius $\mathrm{L}$ extracts (hexane, ethyl acetate and methanol) in addition to semi-purified fraction (No. 12) as described earlier (Nair et al., 2005). The plates were dried and antioxidant activity was detected by spraying 0.2\% 2,2-diphenyl-2-picrylhydrazyl (DPPH) in methanol onto TLC plates. The development of yellow or white spots against a purple background indicated the presence of antioxidant compound.

\section{Preparation of silver nanoparticles (Ag-NPs)}

Ten $\mathrm{mg}$ of $R$. vesicarius $\mathrm{L}$. methanolic extract was directly dissolved in $100 \mathrm{~mL}$ of $1 \mathrm{mM}$ AgNO3 aqueous solution with stirring at room temperature. The $\mathrm{pH}$ of the obtained solutions was adjusted to $10 \mathrm{by} \mathrm{KOH}$. After that, the reaction mixture was kept on a magnetic stirrer for 30 min under constant heating $\left(70{ }^{\circ} \mathrm{C}\right)$. The reduction of $\mathrm{Ag}+$ ions to silver nanoparticles was monitored by visual inspection of the colour change in solution and was apparent immediately after the beginning of the reaction. Particles synthesized with methanolic extract were designated Ag-NPs-Me. The nanoparticles were repeatedly centrifuged at 20,000xg for $30 \mathrm{~min}$ and washed with sterile bi-distilled water before further analysis (Khattak et al., 2019).

\section{Characterization of Ag-NPs-Me}

\section{UV-vis spectrophotometric analysis}

The colour change of the reaction medium was monitored initially by periodic sampling of reaction solutions and then by measuring its UV-VIS absorption. The aliquots of reaction mixture were analysed by Uv-visible spectrophotometer in the range of 200-800 $\mathrm{nm}$ as described by Khattak et al. (2019).

\section{Fourier Transform Infrared (FTIR) spectroscopy}

Fourier transform infrared spectroscopy (FTIR) analysis was done for methanolic extract of Rumex vesicarius $\mathrm{L}$ and silver NPs-Me with Shimadzu FTIR spectrometer at room temperature over the range of 4000$400 \mathrm{~cm}^{-1}$ at a resolution of $3 \mathrm{~cm}^{-1}$ in $\mathrm{KBr}$ pellets. 


\section{Blending of plant extract and fractions with BHT as synthetic standard}

The methanolic extract of $R$. vesicarius $L$ as a promising extract and the pure compound separated from promising fraction (No. 12) were used for the determination of its antioxidant activity using DPPH method (as mentioned before) after blending with synthetic antioxidant standard (BHT) at $100 \mathrm{ug} / \mathrm{ml}$ as described by Shalaby and Shanab (2013).

\section{Statistical analysis}

Values are analysed as means \pm SE or SD. Statistical analysis was done utilizing "costat" statistic computer program. Statistical analysis was established on One-way analysis of variance ANOVA followed by student-Newman Keuls test, and least significant difference (LSD) at $\mathrm{P}<0.05$.

\section{Results and Discussion}

\section{Phytochemical screening}

A lot of medicinal plants are considered to be a biochemical factory as it contains multitude of active ingredients or secondary metabolites such as phenolic compounds, flavonoids, alkaloids, plant acids and glycosides.

The preliminary qualitative screening for phytochemicals of $R$. vesicarius L. successive extracts revealed that the secondary metabolites such as flavonoids, phenols, terpenoids and tannins were detected in the examined three organic extracts (Table 2). However, only methanolic extract contains all secondary metabolites tested (terpenoids, saponin, phenolic, flavonoids, carbohydrates, tannins and alkaloids). Many phytochemicals and other microelements like ascorbic acid, tocopherol, carotenoids, flavonoids, anthocyanins, have antioxidant properties (Abdel-Rahim et al., 2010; Shallan et al., 2010; Afify et al., 2011, 2012; El-Beltagi et al., 2017; Abd El-Maksoud et al., 2018; Mohamed et al., 2018a, b).

Table 2. Phytochemical screening of successive extracts from $R$. vesicarius $\mathrm{L}$.

\begin{tabular}{|c|c|c|c|}
\hline \multirow{2}{*}{ Phytochemical com } & \multicolumn{3}{|c|}{ Plant successive extracts } \\
\cline { 2 - 4 } & n-Hexane & Ethyl acetate & + \\
\hline Terpenoids & + & + & + \\
\hline Phenolic & + & + & + \\
\hline Carbohydrates & - & + & + \\
\hline Tannins & + & - & + \\
\hline Saponin & - & + & + \\
\hline Alkaloids & - & + & + \\
\hline Flavonoids & + & & + \\
\hline
\end{tabular}

+: present; -: absent

These results were in agreement with previous data obtained by Panduraju et al. (2009), Amira et al. (2011), Hariprasad and Ramakrishnan (2011), Husain Khan et al. (2014), Al Aboody (2015), Shalaby and Hameed (2020). as they reported the presence of different natural products in various extracts of $R$. vesicarius L. such as tannins, plant acids, phenolic, alkaloids, steroids, amino acids derivatives and glycosides. These active compounds are considered to be antifungal, antibacterial, antioxidant and antitumor agents as recorded by (Rao, 2003; Alberto et al., 2006; Stevic et al., 2010; El-Beltagi, 2011; Imran et al., 2011; Khan et al., 2014).

Antioxidant activity of $R$. vesicarius $L$. successive extracts

$\mathrm{DPPH}$ and ABTS methods are widely applied to determine the free radical scavenging effect of different antioxidant agents. The DPPH and ABTS possess scavenging abilities due to presence of the hydrogen or 
electron donating activities of antioxidant agents. When DPPH and ABTS results are investigated, it was observed that antioxidant activity has increased in a dose-dependent manner (Ahmeda et al., 2020).

The antioxidant activity of successive extracts from $R$. vesicarius $\mathrm{L}$. was evaluated using DPPH and ABTS radical scavenging method. The obtained results that are recorded in Table 3, revealed that, both methods go parallel and were shown to be dependent on both concentration of extract and incubation time.

The obtained results reported that methanolic extract recorded significantly highest antioxidant activity against both methods (DPPH and ABTS radical) by $79.3 \pm 2.4$ and $78.8 \pm 2.9 \%$ at $100 \mu \mathrm{g} \mathrm{mL}^{-1}$ in addition to $88.6 \pm 3.1$ and $89.5 \pm 1.8 \%$ at $200 \mu \mathrm{gL}^{-1}$ respectively during $30 \mathrm{~min}$ of incubation as shown in Table (2) followed by ethyl acetate extract by $71.8 \pm 4.1$ and $76.1 \pm 1.8 \%$ at $100 \mu \mathrm{g} \mathrm{mL}^{-1}$ in addition $82.0 \pm 0.9$ and $84.3 \pm 1.1 \%$ at $200 \mu \mathrm{g} \mathrm{mL}^{-1}$ respectively followed by $\mathrm{n}$-hexane extract and compared with BHT as synthetic standard which recorded the highest percentage as antioxidant against both radical methods by $92.8 \pm 3.2$ and $93.0 \pm 2.1 \%$ at $200 \mu \mathrm{g} \mathrm{mL}-1$ against DPPH and ABTS respectively. These results were in agreement with the results obtained by Al Aboody (2015) who mentioned that the maximum percentage of DPPH activity by testing different extracts of $R$. vesicarius $\mathrm{L}$. extracts was recorded in ethyl acetate extract followed by distilled water and the lowest activity percentage was exhibited by $n$-hexane extract.

Table 3. Antioxidant activity (\%) of successive extracts of $R$. vesicarius L. against DPPH and ABTS at 100 and $200 \mu \mathrm{g} \mathrm{mL}^{-1}$

\begin{tabular}{|c|c|c|c|c|}
\hline \multirow{2}{*}{ Extract } & \multicolumn{2}{|c|}{ DPPH } & \multicolumn{2}{c|}{ ABTS } \\
\cline { 2 - 5 } & $100 \mu \mathrm{g} \mathrm{mL}^{-1}$ & $200 \mu \mathrm{g} \mathrm{mL}-1$ & $100 \mu \mathrm{g} \mathrm{mL} \mathrm{m}^{-1}$ & $200 \mu \mathrm{gLL}^{-1}$ \\
\hline n-Hexane & $54.3^{\mathrm{d}} \pm 3.2$ & $68.5^{\mathrm{c}} \pm 1.5$ & $56.5^{\mathrm{c}} \pm 4.3$ & $72.4^{\mathrm{c}} \pm 1.9$ \\
\hline Ethyl acetate & $71.8^{\mathrm{c}} \pm 4.1$ & $82.0^{\mathrm{b}} \pm 0.9$ & $76.1^{\mathrm{b}} \pm 1.8$ & $84.3^{\mathrm{b}} \pm 1.1$ \\
\hline Methanol & $79.3^{\mathrm{b}} \pm 2.4$ & $88.6^{\mathrm{a}} \pm 3.1$ & $78.8^{\mathrm{b}} \pm 2.9$ & $89.5^{\mathrm{ab}} \pm 1.8$ \\
\hline BHT & $89.4^{\mathrm{a}} \pm 1.4$ & $92.8^{\mathrm{a}} \pm 3.2$ & $89.9^{\mathrm{a}} \pm 0.8$ & $93.0^{\mathrm{a}} \pm 2.1$ \\
\hline
\end{tabular}

Data are given as mean $\pm S E(n=3){ }^{a, b}$ and $c$ Means within the same column with different letters are significantly differed $(\mathrm{p}<0.05)$.

Determination of phenolic compounds in the three extracts revealed that, absolute methanol extract has recorded the highest percentage (83.7as $\mathrm{mg} \mathrm{GAE} / \mathrm{g}$ ) followed by ethyl acetate ( $71.5 \mathrm{mg}$ GAE/g) and finally $\mathrm{n}$ hexane with $35.70 \mathrm{mg}$ GAE/g as shown in Figure 1.

In this regard, methanolic extract of $R$. vesicarius $\mathrm{L}$ has recorded the highest antioxidant activity which may be mainly due to its contents from natural products as shown in Table 1 and highest amount of phenolic compounds as shown in Figure 1. These results are in agreements with the results obtained by Shanab et al. (2012); Aly et al. (2013); Aboul-Enein et al. (2014); Akladious and Mohamed, 2017; El-Fayoumy et al. (2021) they reported that there is strong correlation between the antioxidant activity (determined by DPPH and ABTS) and phenolic compounds concentration in algae and plant species. 


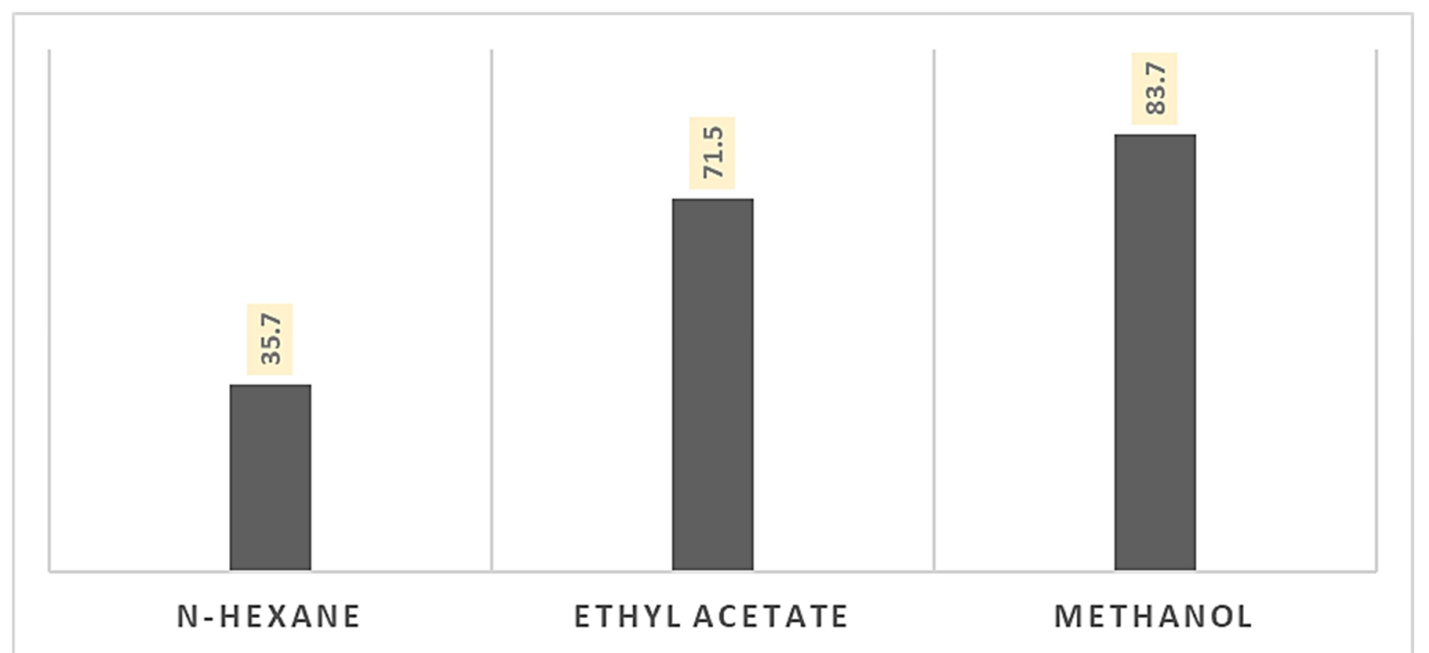

Figure 1. Phenolic compounds content (as $\mathrm{mg} \mathrm{GAE} / \mathrm{g}$ ) of successive extracts from $R$. vesicarius $\mathrm{L}$

\section{Antioxidant activity of semi-purified fractions}

Twenty-two Fractions were separated and identified from methanolic extract (as promising antioxidant extract) of $R$. vesicarius $\mathrm{L}$. DPPH and ABTS radical methods were used for determination the antioxidant activity of each fraction at $100 \mu \mathrm{g} \mathrm{mL}^{-1}$. The obtained results in Table 4 indicated that fraction No. 12 show the highest biological activities as antioxidant against both DPPH and ABTS methods by 75.8 and $77.4 \%$ respectively, followed by fraction No. No. 9 by 68.4 and $68.9 \%$ respectively then fraction 11 by 65.3 and $67.4 \%$ respectively.

Table 4. Antioxidant activity (\%) of semi-purified fractions of methanolic extract from $R$. vesicarius against DPPH and ABTS at $100 \mu \mathrm{g} \mathrm{mL}$

\begin{tabular}{|c|c|c|c|c|c|}
\hline Fraction no. & Against DPPH & Against ABTS & Fraction no. & Against DPPH & Against ABTS \\
\hline 1 & $5.1^{\mathrm{k}} \pm 0.3$ & $6.0^{\mathrm{h}} \pm 0.7$ & 12 & $75.8^{\mathrm{a}} \pm 1.1$ & $77.4^{a} \pm 1.8$ \\
\hline 2 & $4.6^{\mathrm{kl}} \pm 0.0$ & $5.2^{\mathrm{h}} \pm 0.7$ & 13 & $3.5^{1} \pm 0.1$ & $5.9^{h} \pm 0.3$ \\
\hline 3 & $6.7^{k} \pm 0.2$ & $6.6^{\mathrm{h}} \pm 0.0$ & 14 & $33.3^{\mathrm{fg}} \pm 2.0$ & $32.5^{\mathrm{e}} \pm 0.6$ \\
\hline 4 & $6.7^{\mathrm{k}} \pm 1.0$ & $6.7^{\mathrm{h}} \pm 0.4$ & 15 & $49.4^{\mathrm{d}} \pm 1.2$ & $51.1^{c} \pm 3.2$ \\
\hline 5 & $8.3^{k} \pm 0.3$ & $9.2^{\mathrm{gh}} \pm 1,0$ & 16 & $49.4^{\mathrm{d}} \pm 1.2$ & $50.8^{c} \pm 1.7$ \\
\hline 6 & $5.1^{\mathrm{k}} \pm 0.0$ & $5.0^{h} \pm 0.3$ & 17 & $41.2^{\mathrm{e}} \pm 0.4$ & $39.6^{\mathrm{d}} \pm 2.8$ \\
\hline 7 & $3.5^{1} \pm 0.0$ & $3.9^{\mathrm{h}} \pm 0.4$ & 18 & $36.7^{f} \pm 1.4$ & $37.5^{\mathrm{d}} \pm 1.9$ \\
\hline 8 & $56.4^{\mathrm{c}} \pm 3.1$ & $55.0^{c} \pm 0.3$ & 19 & $30.2^{\mathrm{gh}} \pm 0.0$ & $31.2^{\mathrm{e}} \pm 0.7$ \\
\hline 9 & $68.4^{\mathrm{b}} \pm 0.9$ & $68.9^{\mathrm{b}} \pm 4.1$ & 20 & $30.2^{\mathrm{gh}} \pm 1.3$ & $30.4^{\mathrm{e}} \pm 0.5$ \\
\hline 10 & $16.7^{\mathrm{i}} \pm 1.1$ & $20.5^{\mathrm{f}} \pm 1.2$ & 21 & $13.4^{\mathrm{ij}} \pm 0.5$ & $12.7^{\mathrm{g}} \pm 1.0$ \\
\hline 11 & $65.3^{b} \pm 1.5$ & $67.4^{\mathrm{b}} \pm 0.7$ & 22 & $12.0^{\mathrm{i}} \pm 0.1$ & $14.6^{\mathrm{g}} \pm 0.5$ \\
\hline
\end{tabular}

Data are given as mean \pm SE $(n=3)$. a, band c Means within the same column with different letters are significantly differed $(\mathrm{p}<0.05)$.

\section{GC-MS analysis of successive extracts}

The GC-MS analysis of successive extracts of $R$. vesicarius showed the presence of various phytocomponents. The phytocomponents of each extract are presented separately in Table 5 and the GC-MS chromatogram with peak area of each extract is also shown in Figure 2 . Totally 35 constituents were identified in $R$. vesicarius from all the three successive extracts. Methanol extract has recorded the highest number of (19) phytoconstituents, while lower number of (6) phytoconstituents was observed in hexane extract including both major and minor constituents. Three constituents were commonly present in all the three extracts as the 
following 9,12,15-Octadecatrienoic acid; 2H-1-Benzopyran-6-ol, 3,4-dihydro-2,8-dimethyl-2-(4,8,12trimethyltridecyl) and gamma-tocopherol.

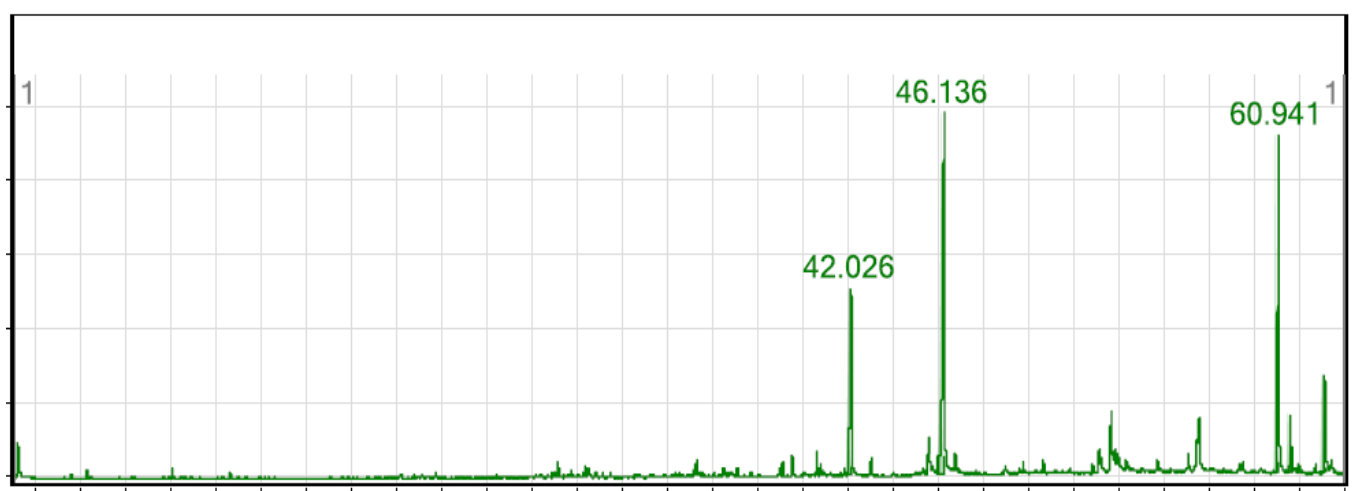

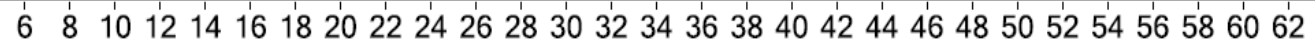

a)

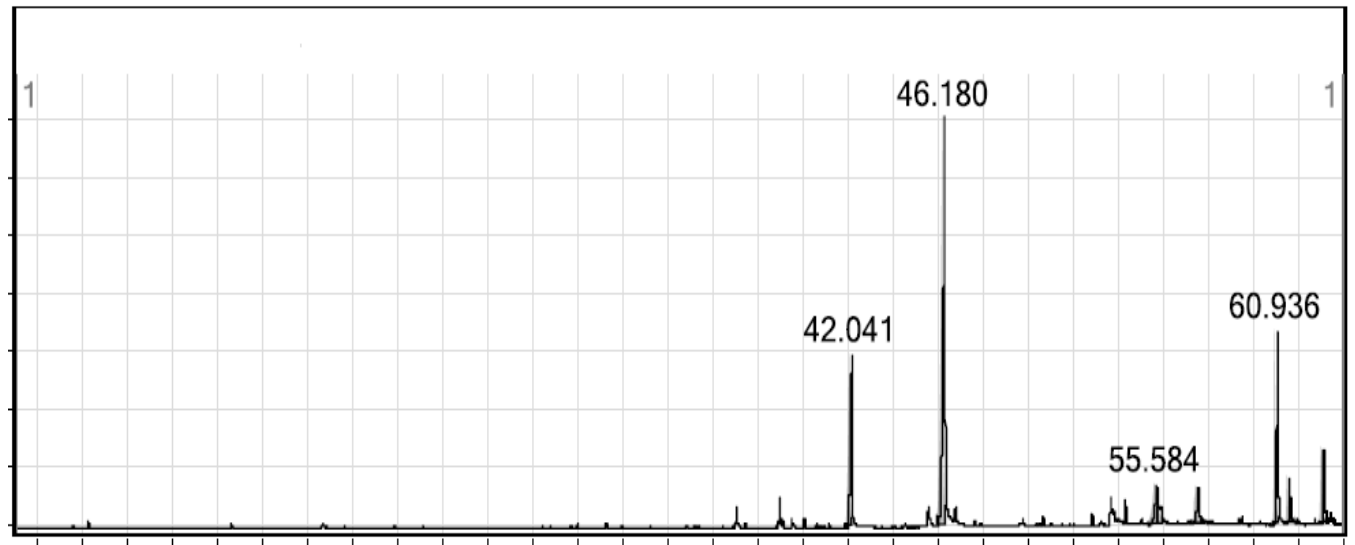

68101214161820222426283032343638404244464850525456586062

b)

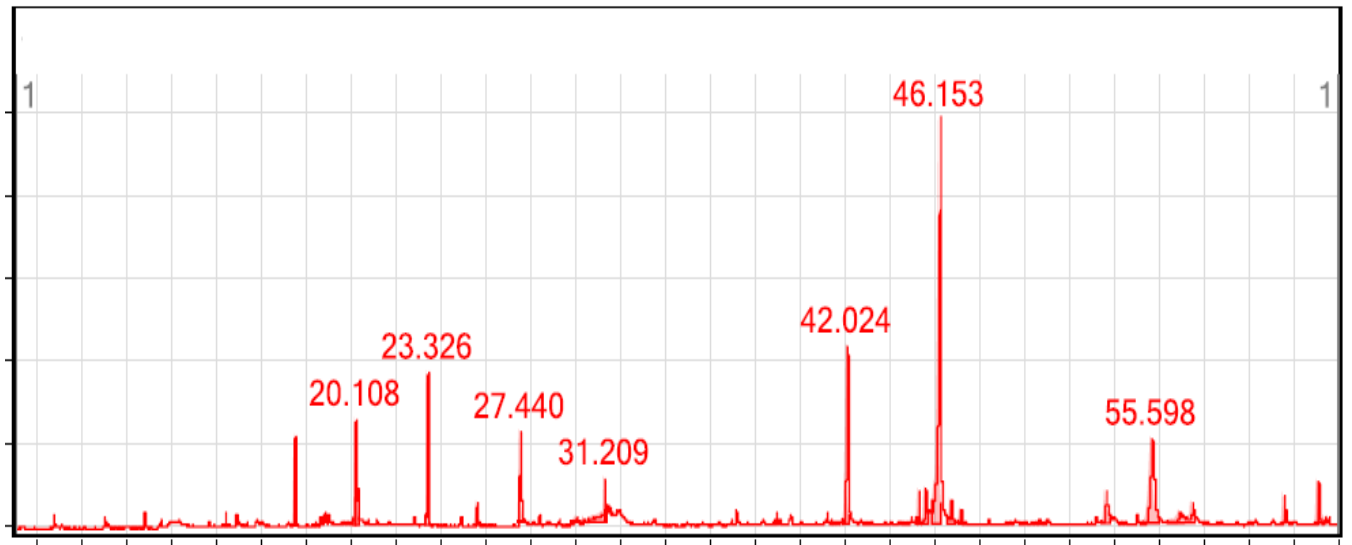

68101214161820222426283032343638404244464850525456586062

Figure 2. GC-MS chromatogram of $R$. vesicarius

c)

a) hexane extract (above chromatogram); b) ethyl acetate extract (center); c) methanol extract (down). 
The methanol extract of $R$. vesicarius showed 19 constituents, the major constituents were 9,12,15octadecatrienoic acid (30.8\%); gamma-sitosterol (12.7\%) and ascorbic acid 2, 6-dihexadecanoate (9.68\%). All of these major compounds represent antioxidant activity as reported by Sayik et al. (2017); Baskar et al. (2012) and Begum et al. (2017). In addition to 11 compounds from the total of 19 compounds of methanol extract reported antioxidant activity as shown in Table 5. These findings were going parallel with the results obtained in Table 3 and Figure 3.

The ethyl acetate extract of $R$. vesicarius revealed presence of 10 constituents (Table 5). The major constituents were 9,12,15-octadecatrienoic acid (45.34\%), n-hexadecanoic acid (14.1\%) and pentatriacontane (12.62\%). Along with major constituents, minor constituents were also reported. Moreover, the hexane extract of the plant showed the lowest constituent's number (only 6 constituents) as shown in (Table 5). The major constituents were 9,12,15-octadecatrienoic acid (41.11\%), pentatriacontane $(24.02 \%)$ and ascorbic acid 2, 6dihexadecanoate (18.91\%). Along with major constituents, minor constituents were also recorded. The GCMS chromatogram with peak area was given in Figure 2. The obtained results were in agreement with the results obtained by Hariprasad and Ramakrishnan (2011); Ammar et al. (2015).

\section{Antiradical activity of methanolic extract and its fraction}

Antiradical activity of methanolic extract and fraction No. 12 (chloroform: ethyl acetate 40:60 v/v) were determined using both DPPH and ABTS radical scavenging methods at $100 \mu \mathrm{g} \mathrm{mL} \mathrm{L}^{-1}$ during the incubation times $(30-300 \mathrm{sec})$.

The obtained results recorded in Figures ( $3 \mathrm{a}$ and $\mathrm{b}$ ), revealed that, the antiradical activity was shown to be incubation time dependent. Methanolic extract showed the highest antiradical activity represented as AU or antiradical unit (0.056 and 0.061) against DPPH and ABTS respectively when compared with fraction No. 12 by $\mathrm{AU}(0.026$ and 0.036$)$ at 300 seconds of incubation.

From the obtained results of antioxidant and antiradical activity of crude extracts and obtained fractions shown in Tables 3 and 4 and Figure 3, it could be concluded that the activity was decreased upon separation of the fractions and it was lower than that of the crude extract. The potent antioxidant activity manifested by the crude extract in comparison with those of the separated fractions may be due to the synergistic action of the collective biologically active compounds of one or more of the twenty-two fractions in the crude extract. In addition, the crude extract may have secondary metabolites in very low concentration which enhance the active principles and increase the antiradical and antioxidant activity. This suggestion was previously confirmed by Chu et al. (2010) and Aboul Enein et al. (2014) they reported that crude methanolic extract of Arthrospirasp gave higher antioxidant activity than pure chemical compounds. They mentioned that the extract might contain other constituents (e.g. flavonoids, phenolic compounds) which recorded a higher combined antioxidant activity than pure compound. The synergistic effect of a wide spectrum of antioxidants may be more efficiency than the activity a single antioxidant.

The obtained results were found to be in agreement with those recorded by Nivas et al. (2010) and Tiryitis and Bartosz (2010). In the same context Kaviarasan et al. (2007) studied the antiradical and antioxidant activities (by ABTS and DPPH) using aqueous methanolic extract of fenugreek seeds and they found that the activities could be correlated with the phenolic concentration in the extract. The same results were reported by Huyut et al. (2017) who mentioned that there was a very significant relationship between antiradical, antioxidant activities and total content of phenolic compounds. 
Table 5. List of phytochemical constituents (as Relative percentage) in different successive extracts of Rumex vesicarius $\mathrm{L}$.

\begin{tabular}{|c|c|c|c|c|c|c|c|}
\hline \multirow[b]{2}{*}{ S.No. } & \multirow[b]{2}{*}{ Rt } & \multirow[b]{2}{*}{ Chemical name } & \multicolumn{3}{|c|}{ Extract } & \multirow{2}{*}{$\begin{array}{l}\text { Biological activities } \\
\text { as antioxidant }\end{array}$} & \multirow[b]{2}{*}{ References } \\
\hline & & & Hexane & $\begin{array}{c}\text { Ethyl } \\
\text { acetate }\end{array}$ & Methanol & & \\
\hline 1 & 17.298 & $\begin{array}{c}\text { 4H-Pyran-4-one, 2,3- } \\
\text { dihydro-3,5-dihydroxy-6- } \\
\text { methyl }\end{array}$ & - & - & 3.68 & Antioxidant activity & Sayik et al. (2017) \\
\hline 2 & 20.028 & Coumaran & _ & _ & 3.72 & Antioxidant activity & Ilya et al. (2018) \\
\hline 3 & 20.159 & $\begin{array}{l}\text { 1-Propanone, 2-methyl-1-[4- } \\
\text { (methylthio) phenyl]-2-(4- } \\
\text { morpholinyl) }\end{array}$ & - & - & 1.82 & - & - \\
\hline 4 & 23.266 & $\begin{array}{c}\text { N,N,N-Trimethyl-1,4- } \\
\text { phenylenediamine }\end{array}$ & - & - & 4.85 & - & - \\
\hline 5 & 25.408 & $\begin{array}{l}\text { Methyl-5-oxo-2- } \\
\text { pyrrolidinecarboxylate }\end{array}$ & - & - & 1.52 & Antioxidant activity & Wondrak et al. (2008) \\
\hline 6 & 27.372 & $\begin{array}{c}\text { 2-hydroxy-4- } \\
\text { methylbenzaldehyde }\end{array}$ & - & - & 4.61 & Antioxidant activity & Wang et al. (2010) \\
\hline 7 & 29.758 & Heptose & _ & _ & 0.65 & - & _ \\
\hline 8 & 30.146 & Folic acid & - & - & 0.4 & Antioxidant activity & Atteia et al. (2009) \\
\hline 9 & 30.538 & 2-cyclohexylpiperidine & - & - & 4.83 & & \\
\hline 10 & 31.305 & Formy glutamine & _ & _ & 0.3 & Antioxidant activity & Zabot etal. (2017) \\
\hline 11 & 41.868 & n-Hexadecanoic acid & - & 14.1 & - & Antioxidant activity & $\begin{array}{c}\text { Sheela and } \\
\text { Uthayakumaria (2013) }\end{array}$ \\
\hline 12 & 42.026 & $\begin{array}{l}\text { Ascorbic acid 2, 6- } \\
\text { dihexadecanoate }\end{array}$ & 18.91 & - & 9.68 & Antioxidant activity & Begum et al. (2017) \\
\hline 13 & 45.305 & Oleic acid & _ & _ & 3.68 & _ & _ \\
\hline 14 & 46.136 & $\begin{array}{c}9,12,15-\text { Octadecatrienoic } \\
\text { acid }\end{array}$ & 41.11 & 45.34 & 30.8 & Antioxidant activity & Sayik et al. (2017) \\
\hline 15 & 46.537 & Paromomycin & _- & _ & 1.96 & _ & - \\
\hline 16 & 55.302 & beta-Sitosterol & - & 7.59 & - & & \\
\hline 17 & 55.726 & gamma-Sitosterol & - & 2.48 & 12.7 & Antioxidant activity & Baskar et al. (2012) \\
\hline 18 & 57.229 & 11-Octadecenal & _ & 5.77 & _ & _ & _ \\
\hline 19 & 57.682 & 2-Myristynoyl pantetheine & - & 0.64 & 4.0 & _- & - \\
\hline 20 & 60.941 & Pentatriacontane & 24.02 & 12.62 & _ & _ & _ \\
\hline 21 & 61.485 & $\begin{array}{c}\text { 2H-1-Benzopyran-6-ol, 3,4- } \\
\text { dihydro-2,8-dimethyl-2- } \\
\text { (4,8,12-trimethyltridecyl) }\end{array}$ & 5.71 & 4.23 & 7.62 & - & - \\
\hline 22 & 61.629 & $\begin{array}{l}\text { 2-Morpholino ethane } \\
\text { sulfonic acid }\end{array}$ & 0.49 & - & - & Antioxidant activity & Baker et al. (2007) \\
\hline 23 & 61.79 & Dihydroxanthin & _- & 0.75 & 0.4 & Antioxidant activity & Khan et al. (2019) \\
\hline 24 & 62.996 & gamma-Tocopherol & 9.76 & 6.47 & 2.79 & Antioxidant activity & Abdulla et al. (2018) \\
\hline
\end{tabular}

Meanwhile, Sroka (2006) determined the antiradical and antioxidant efficiency in 100\% and 50\% methanol extracts of tea samples (green and black). He mentioned that $100 \%$ methanol extracted the tea tannins. Higher antiradical activity unit TAU/g was those of green and black tea leaves in ethyl acetate fraction of aqueous methanol extract. Moreover, Melichacova et al. (2010) revealed that the antioxidant activity of $50 \%$ methanol extract of both sweet cherry and tart cherry fruit were due to and correlated with the soluble phenolics in tested solvent. 


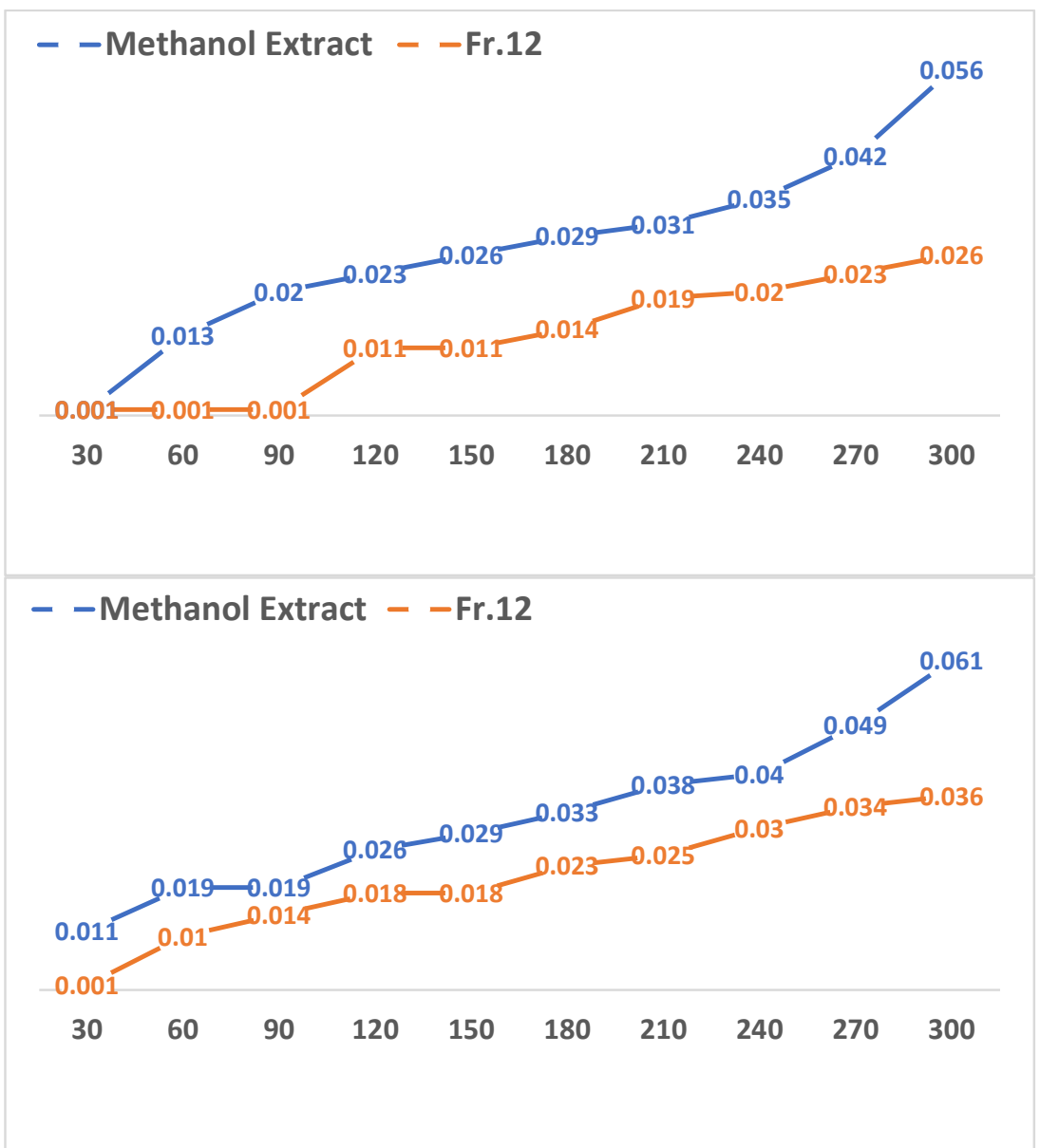

Figure 3. Antiradical Unit (AU) against DPPH (above) and ABTS (down) of methanolic extract and pure fraction (No.12) from $R$. vesicarius at $100 \mu \mathrm{g} / \mathrm{ml}$

\section{Bio-autography for antioxidant activity}

Antioxidant potential compounds on TLC plates were identified in situ through using of DPPH reagent (Figure 4). The fractions produced yellowish or white bands on the purple background were considered as strong antioxidants. All of Rumex vesicarius $\mathrm{L}$ extracts showed white or yellow band (antioxidant compounds) being formed at the region at Rf $0.287,0.81$ and 0.90 on exposure to DPPH, in addition to single antioxidant compound separated from fraction No. 12 with white colour after sprayed by DPPH reagent with Rf 0.081 as shown In Figure 4. DPPH reagent with method measures electron-donating activity (free radical scavenging activity) of compounds and provides an evaluation of antioxidant activity (Prema et al., 2012).

Semi-purified antioxidant constituent (from fraction No. 12) was scrapped and collected after performing silica gel preparative TLC separation of methanolic extract. The sample obtained from preparative TLC was subjected to GC-MS analysis to identify the antioxidant compound (Figure 5).

\section{GC-MS of pure compound}

One main compound was identified from fraction No. 12 of methanolic extract using GC-MS (Figure 5) after scratching from preparative TLC. The identified compound was $1-(+)$ - Ascorbic acid 2, 6dihexadecanoate (with molecular weight $652.9 \mathrm{Da}$ and molecular formula $\mathrm{C}_{38} \mathrm{H}_{68} \mathrm{O}_{8}$ ) which been found in different saudi medicinal plants (Ara et al., 2012) and also reported to have antioxidant activity by Begum et al. (2017). The efficiency of ascorbates derivatives as antioxidants is dependent upon the substrate and the compounds to be protected. Because the 2- and 3-positions of ascorbic acid must be unsubstituted, the two free 
radicals formed at these positions may be intermediates in scavenging oxygen and inhibiting radical formation at double bonds.

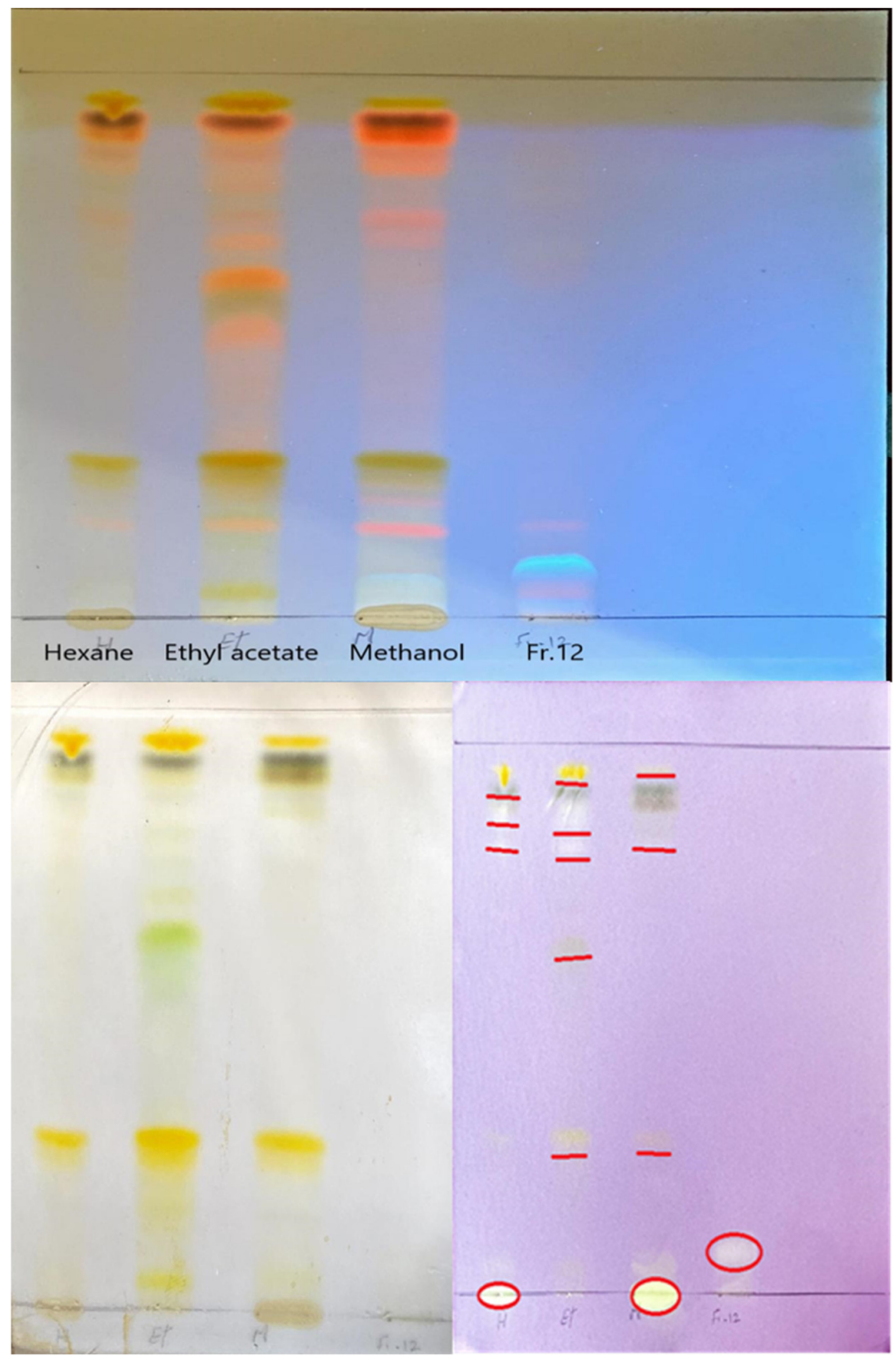

Figure 4. TLC chromatogram of $R$. vesicarius extracts and fraction No. 12 (under short UV lamp at 254 $\mathrm{nm}$ ) and TLC- bioautography of various extracts and fraction No. 12 (Sprayed with and without DPPH reagent)

Upon mixing the promising absolute methanol extract (recorded $79.3 \%$ antioxidant activity) with the standard synthetic antioxidant BHT in gradually proportion (from 100\% BHT to $100 \%$ of methanol extract or pure compound), the results in Table 6 , revealed presence of closely similar activities (with very few differences) in all extracts or pure compounds and BHT proportions. This means that the antioxidant activity of standard BHT was increased by each proportion of extract with an obvious synergism between them and these results were in agreement with the results obtained by Shalaby and Shanab (2013). Also, the obtained results revealed that the effect of the crude extract was more effective when mixing with BHT when compared with pure compound separated from methanolic extract as shown in Table 6. 

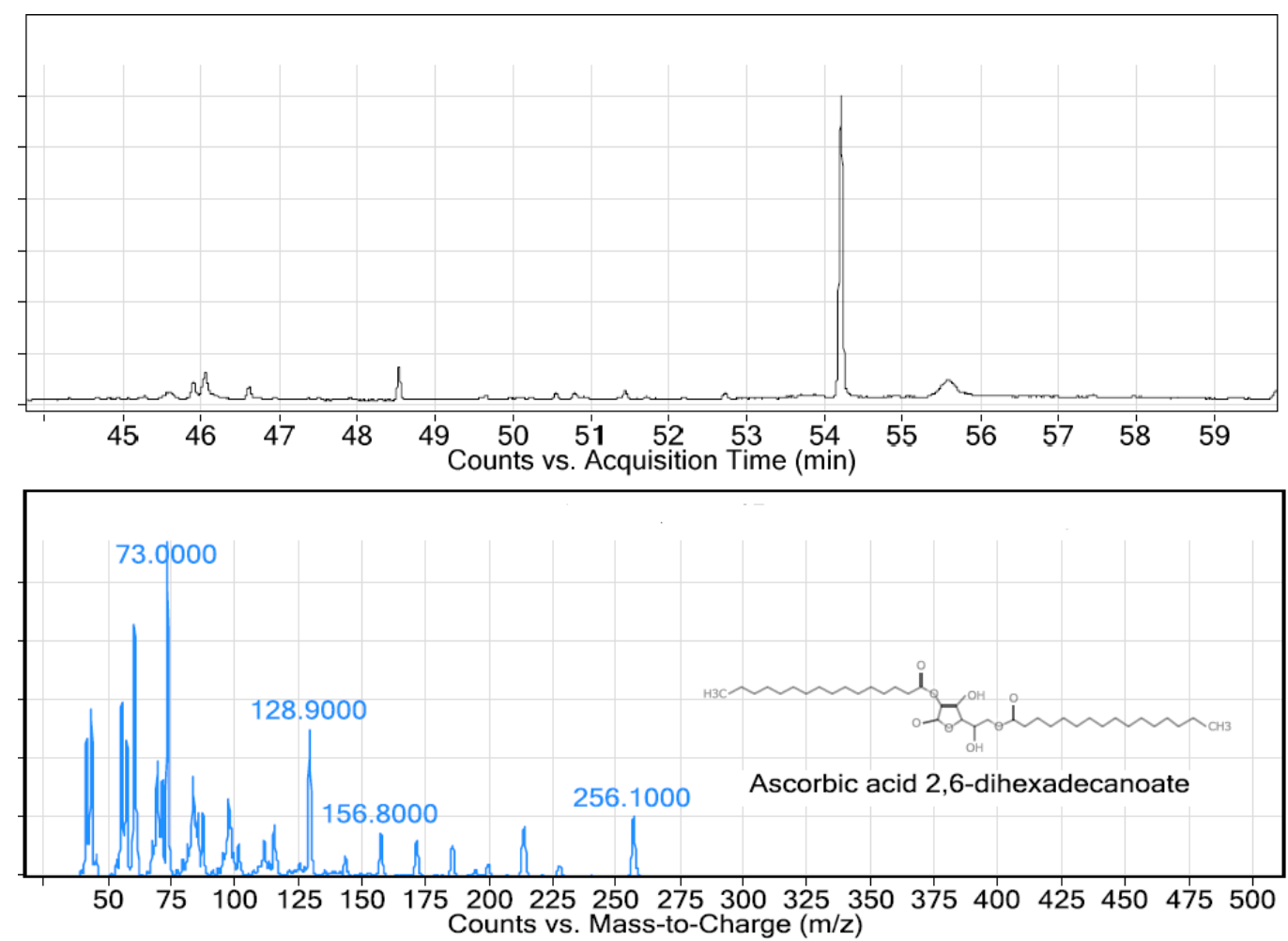

Figure 5. GC-MS chromatogram of pure compound isolated from fraction No. 12 of crude methanolic extract of $R$. vesicarius

Table 6. Antioxidant activity (\%) of synthetic antioxidant (BHT, $100 \mu \mathrm{g} \mathrm{m}^{-1}$ ) blending with methanolic extract and pure compound (scratched from fraction No. 12 at $100 \mu \mathrm{g} / \mathrm{ml}$ ) of $R$. vesicarius at different ratio against DPPH assay

\begin{tabular}{|c|c|c|c|}
\hline Sample & Antioxidant $\%$ & Sample & Antioxidant \% \\
\hline $100 \% \mathrm{BHT}$ & $89.4^{\mathrm{a}} \pm 1.4$ & $100 \% \mathrm{BHT}$ & $89.4^{\mathrm{a}} \pm 1.4$ \\
\hline $90 \%$ BHT: $10 \%$ Me extract & $86.0^{\mathrm{b}} \pm 2.6$ & $90 \%$ BHT: $10 \%$ pure compound & $83.1^{\mathrm{b}} \pm 0.8$ \\
\hline $80 \%$ BHT: $20 \%$ Me extract & $85.9^{\mathrm{b}} \pm 1.1$ & $80 \%$ BHT: $20 \%$ pure compound & $81.4^{\mathrm{c}} \pm 2.7$ \\
\hline 70\% BHT: 30\% Me extract & $83.2^{c} \pm 0.9$ & $70 \%$ BHT: $30 \%$ pure compound & $80.7^{\mathrm{c}} \pm 3.2$ \\
\hline $60 \%$ BHT: $40 \%$ Me extract & $84.7^{\mathrm{c}} \pm 2.5$ & $60 \%$ BHT: $40 \%$ pure compound & $80.0^{c} \pm 2.0$ \\
\hline 50\% BHT: $50 \%$ Me extract & $84.1^{\mathrm{c}} \pm 1.4$ & $50 \%$ BHT: $50 \%$ pure compound & $79.6^{\mathrm{cd}} \pm 3.2$ \\
\hline 40\% BHT: $60 \%$ Me extract & $82.0^{\text {cd }} \pm 3.0$ & $40 \%$ BHT: $60 \%$ pure compound & $78.9^{\text {cd }} \pm 1.5$ \\
\hline 30\% BHT: 70\% Me extract & $82.7^{\mathrm{cd}} \pm 0.9$ & 30\% BHT: $70 \%$ pure compound & $76.8^{\mathrm{e}} \pm 0.7$ \\
\hline 20\% BHT: $80 \%$ Me extract & $82.5^{\text {cd }} \pm 1.9$ & 20\% BHT: $80 \%$ pure compound & $75.0^{\mathrm{f}} \pm 2.8$ \\
\hline 10\% BHT: $90 \%$ Me extract & $81.0^{\text {ed }} \pm 1.8$ & 10\% BHT: $90 \%$ pure compound & $75.6^{\mathrm{f}} \pm 1.0$ \\
\hline $100 \% \mathrm{Me}$ extract & $79.3^{\text {ed }} \pm 2.4$ & $100 \%$ pure compound & $73.0^{\mathrm{g}} \pm 3.5$ \\
\hline
\end{tabular}

Data are given as mean \pm SE $(n=3)$. ${ }^{\text {a, b and } c}$ Means within the same column with different letters are significantly differed $(\mathrm{p}<0.05)$.

\section{Synthesis of silver nanoparticles (Ag-NPs-Me)}

\section{UV-visible of NPs}

When the methanolic extract of $R$. vesicarius $\mathrm{L}$ was added to silver nitrate solution, $\mathrm{pH}$ was adjusted and the solution was heated. The colour of the reaction was formed immediately and started to be converted gradually from colourless to brown. The intensity of the brown colour increased rapidly by time, from seconds to minutes and remained stable within one hour. It is well known that Ag-NPs-Me have brown colour due to 
their characteristic excitation of surface plasmons in the range of 400-490 nm (Panja et al., 2020). Therefore, a transition of the solution from colourless to brown colour indicates the synthesis of Ag-NPs (Vanaja et al., 2013).

This result means that the methanolic extract of $R$. vesicarius $\mathrm{L}$. have high reduction potential for reduced silver ions and formation of silver nanoparticles. The UV-VIS spectra of synthesized Ag-NPs-Me demonstrated the maximum peak at $390 \mathrm{~nm}$ as shown in Figure 6. which was consistent with the spectra of spherical AgNPs within the wavelength range of $380-450 \mathrm{~nm}$. Similar surface plasmon resonance (SPR) peaks were observed in many studies of green synthesis for silver nanoparticles as reported by several studies (Desai et al., 2012; Ndikau et al., 2017; Yugay et al., 2020).

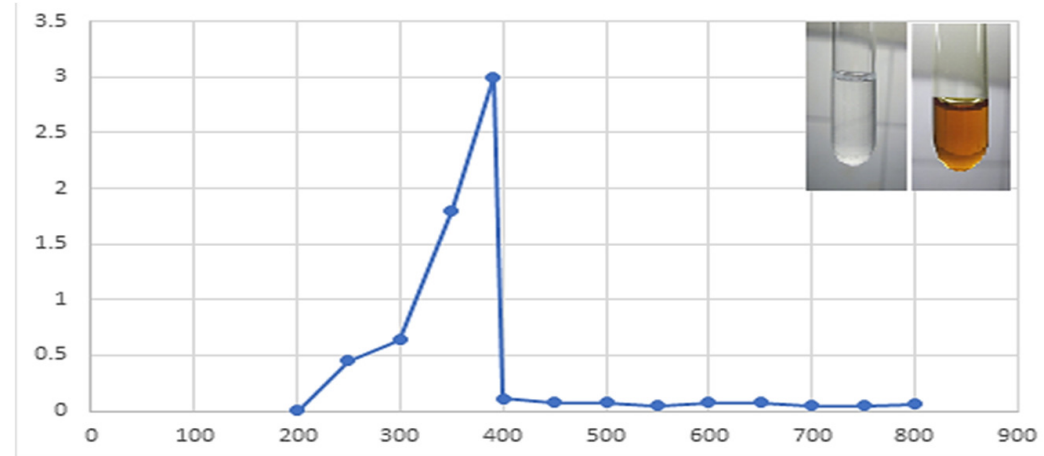

Figure 6. UV-VIS spectra of $R$. vesicarius methanolic extract with SNPs (Ag-NPs-Me); above picture illustrate bio reduction of silver nitrate colorless solution $(1 \mathrm{mM})$ by methanolic $R$. vesicarius extract and formation of plant silver nanoparticles (AgNPs) with brown color source

\section{FTIR of NPs}

FTIR measurements were carried out to identify the promising biomolecules in the Rumex vesicarius $\mathrm{L}$. methanolic extract accountable for the silver ion reduction and also the capping agent liable for the reduced AgNPs stability.

As shown in Figures $7 \mathrm{a}$ and $\mathrm{b}$ and Table 7, the FTIR spectra of methanolic extract and Ag-NPs-Me, respectively, were recorded in the frequency range between 4400 and $350 \mathrm{~cm}^{-1}$ in the mode of $\%$ transmittance (\%T). It was shown that there were slight shifts in the FTIR peaks of $R$. vesicarius $L$ extract $(3383,2948,2834$, 2526, 2052, 1654, 1453, 1412, 1112, 1031 and $\left.663 \mathrm{~cm}^{-1}\right)$ and the synthesized AgNPs (3455, 2067, 1638 and $\left.443 \mathrm{~cm}^{-1}\right)$. The absence of some peaks $\left(2948,2834,2526,1453,1412,1112\right.$ and $\left.1031 \mathrm{~cm}^{-1}\right)$ in the synthesized AgNPs compared to the methanolic extract, and the slight shifts noted in the peaks suggests the involvement of some functional groups in the reduction process. The bands from 3455 up to $3383 \mathrm{~cm}^{-1}$ in the FTIR spectra corresponds to $\mathrm{O}-\mathrm{H}$ stretching vibration, which indicates the presence of alcohol and phenol. It was reported that hydroxyl groups $(\mathrm{O}-\mathrm{H})$ have stronger binding ability with silver ions. It was noted that there were shifts in the FTIR peaks of $R$. vesicarius $L$ synthesized AgNPs $\left(3383,2052\right.$, and $\left.1654 \mathrm{~cm}^{-1}\right)$ when compared to $R$. vesicarius $\mathrm{L}$ extract. This suggests the presence of various functional groups responsible for the reduction of silver ion to the nanoparticles form. The FT-IR analysis suggested that the reasonable mechanism of AgNPs formation may be due to the reduction of $\mathrm{Ag}^{+}$ions that takes place together with oxidation of phenolic components of polyols or other reducing components in plant extract (Gandhi et al., 2020). 
Younes KM et al. (2021). Not Bot Horti Agrobo 49(1):12293

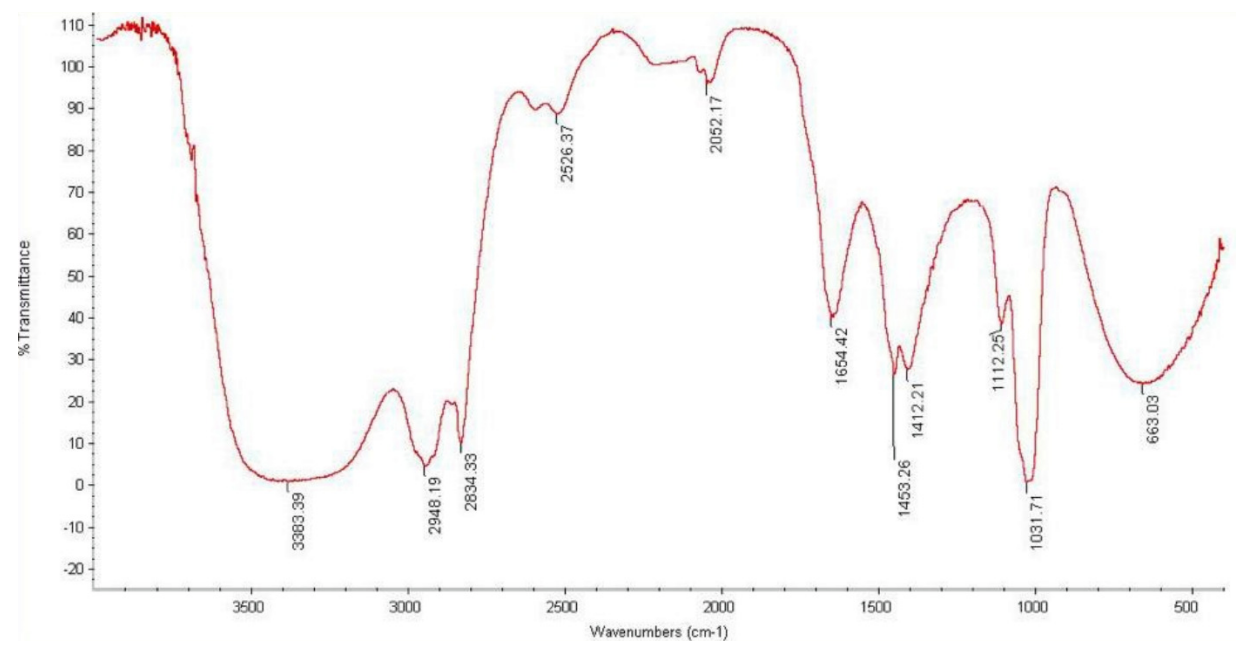

(a)

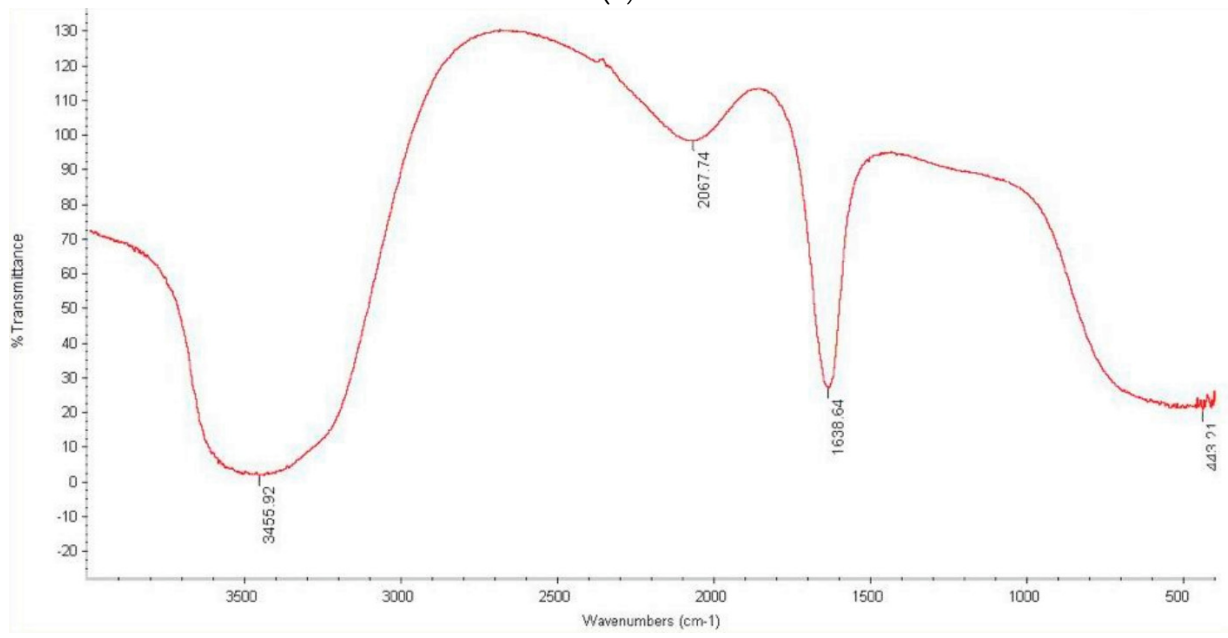

(b)

Figure 7. FTIR spectra of Rumex sp methanolic extract (a) and silver nanoparticles synthesized solution (b)

Table 7. Wavenumbers range of characteristic bands and corresponding assignments for $R$. vesicarius and Ag-NPs-Me

\begin{tabular}{|c|c|c|c|}
\hline \multirow{2}{*}{ Wavenumber range $\left(\mathrm{cm}^{-1}\right)$} & \multirow{2}{*}{ Function groups assigned } & \multicolumn{2}{|c|}{ Sample } \\
\hline & & Methanolic extract & Ag-NPs-Me \\
\hline $3300-4000$ & $\begin{array}{c}\text { Polymeric hydroxyl compound } \mathrm{O}-\mathrm{H} \\
\text { stretching }\end{array}$ & 3383 & 3455 \\
\hline $3100-2723$ & $\begin{array}{c}\text { C-H stretching vibrations specific to } \\
\text { CH3 } \\
\text { and } \mathrm{CH} 2\end{array}$ & $\begin{array}{l}2948 \\
2834\end{array}$ & ND \\
\hline $1700-1630$ & $\begin{array}{c}\mathrm{C}=\mathrm{O} \text { stretching vibration, } \mathrm{C}-\mathrm{N} \\
\text { stretching, Lipids, Ester carbonyl - } \\
\text { COOR and carboxylate ion stretching } \\
\text { (-COO-)- }\end{array}$ & 1654 & 1638 \\
\hline $1600-1400$ & $\begin{array}{l}\text { C-O stretching vibration (amide) and } \\
\text { C-C stretching from phenyl groups, }\end{array}$ & $\begin{array}{l}1453 \\
1412\end{array}$ & ND \\
\hline
\end{tabular}




\begin{tabular}{|c|c|c|c|}
\hline & $\begin{array}{c}\text { COO symmetric stretching, CH2 } \\
\text { bending }\end{array}$ & \\
\hline \multirow{2}{*}{$1150-1000$} & $\begin{array}{c}\text { Stretching vibrations C-O of mono-, } \\
\text { oligo-, }\end{array}$ & 1112 \\
& ND \\
& and carbohydrates, Pyranoid ring & 631 & 443 \\
\hline $690-400$ & Halo compounds (Iodo and bromo) & 663 & . \\
\hline
\end{tabular}

ND: Not detected

Antioxidant activity of $A g-N P$ s-Me of $R$. vesicarius $L$

Regarding the biological activity of synthetic silver nanoparticles from $R$. vesicarius $\mathrm{L}$ methanolic extract, the antioxidant activity of Ag-NPs-Me against DPPH radical was evaluated. The obtained results revealed that green synthesis of SNPs using methanolic extract led to increase of antioxidant activity (with IC $50=53.9 \mu \mathrm{g} / \mathrm{ml}$ ) when compared with crude methanol extract (IC50 $=74.6 \mu \mathrm{g} / \mathrm{ml}$ ) but lower than BHT as synthetic standard $(\mathrm{IC} 50=13.64 \mu \mathrm{g} / \mathrm{ml}$ ) as shown in Figure 8 . These results may be due to that the nanoparticles synthesized using methanolic extract of $R$. vesicarius showed antioxidant activity because of capped phenolic compounds.

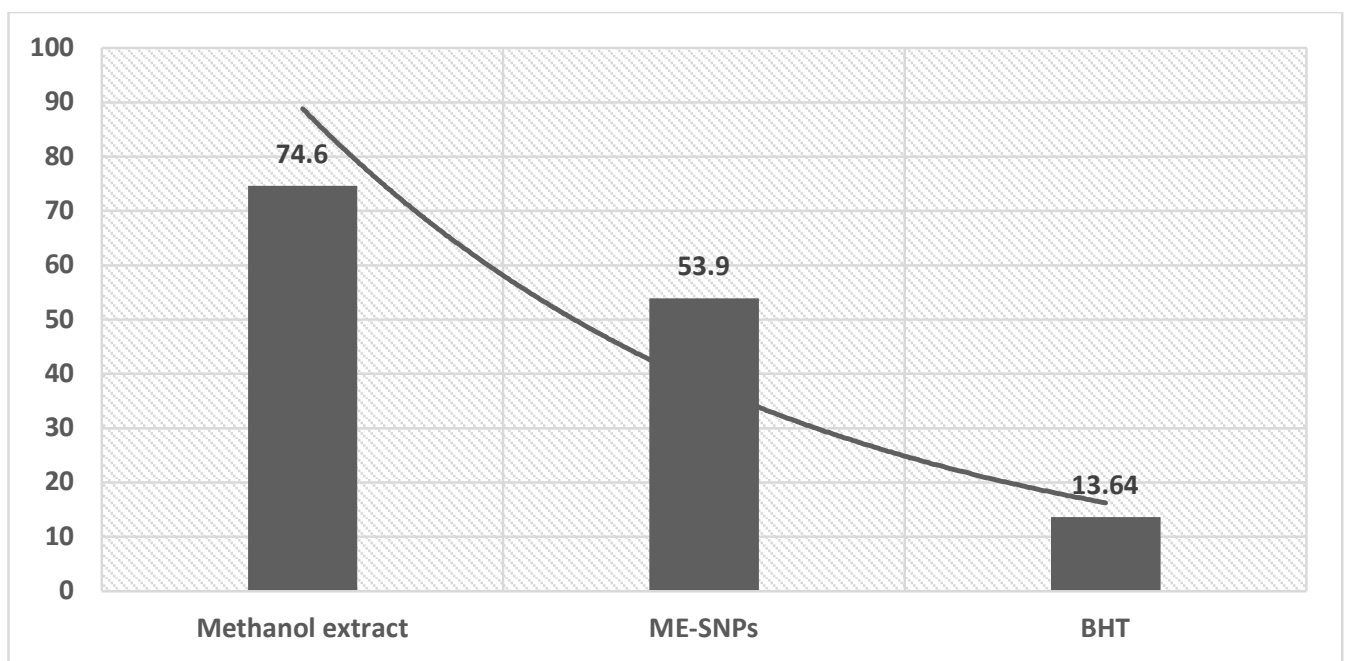

Figure 8. $\mathrm{IC}_{50}\left(\mu \mathrm{g} \mathrm{ml}^{-1}\right)$ of plant methanolic extract and Ag-NPs-Me against DPPH radical compared with BHT as synthetic standard

Phenolic group facilitates the conversion of silver nitrate to AgNPs due to its electron donating ability. These results were in agreement with the results obtained by Yousaf et al. (2020), who mentioned that the methanol-SNPs exhibit greater inhibition of DPPH radicals with IC50 $7.03 \pm 0.31 \mu \mathrm{g} / \mathrm{mL}$. Also, Sudha et al. (2017) who reported that the maximum inhibition of superoxide radical scavenging activity was about $70 \%$ by biosynthesized AgNPs as compared to the activity of butylated hydroxy toluene as synthetic standard (84\%). Moreover, Salari et al. (2019) revealed that the phenols and flavonoids in AgNPs-containing plant extract were $462.69 \mathrm{mg} \mathrm{GAE} / \mathrm{g}$ extract and $386.94 \mathrm{mg}$ QE/g extract respectively, which were significantly greater than native extract. Biosynthesized silver nanoparticles showed a higher antioxidant compared to native extract alone. 


\section{Conclusions}

From the results obtained in the present study, it can be concluded that the crude extracts of $R$. vesicarius L contains a wide variety of secondary metabolites that could serve as antioxidant, antiradical and reducing or capping agents in the synthesis of nanoparticles. Antioxidant and antiradical activity of plant extracts was dependent on concentration of extract and incubation timed. Also, the obtained results conclude that methanolic extract of $R$. vesicarius $L$ recorded the highest antioxidant and antiradical activity when compared with other crude extracts and BHT as synthetic standard. As, the antiradical activity being defined as the ability of a compound to react with free radicals in a single free radical reaction, the calculated antiradical activity units showed the highest values after 300 seconds ( 5 minutes) comparing with antioxidant activity ( 30 min) which is important in time saving and considered more sensitive especially with the electron reacting ABTS radicals. Moreover, the antioxidant activity increased with synthetic Ag-NPs-Me when compare with methanolic extract of $R$. vesicarius $L$. The data also revealed presence of closely similar antioxidant activities in methanolic extract or its pure compounds with BHT when mixed at different proportions.

\section{Authors' Contributions}

Conceptualization: E.A.S., K. M. Y. and H. S. E; Data curation; E.A.S. and K. M. Y. Formal analysis; Funding acquisition; R. M. R. and E. A. S. Investigation; E. A. S., K. M. Y., H. S. E. and H. E. Methodology; E.A.S., K. M. Y., S. R and H. E Project administration; R. M. R., E. A. S and H. S. E. Resources; E. A. S and K. M. Y. Software; E. A. S, S. R and H. E. Supervision; E. A. S., H. S. E. and R. M. R. Validation; E. A. S. and K. M. Y. Writing - original draft; E. A. S., H. S. E and K. M. Y. Writing - review and editing E. A. S., H. A. E., R. M. R., S. R and H. E.

All authors read and approved the final manuscript.

\section{Acknowledgements}

This research has been funded by Scientific Research Deanship at University of Hail-Saudi Arabia through project number RG-191256.

\section{Conflict of Interests}

The authors declare that there are no conflicts of interest related to this article.

\section{References}

Abd El-Maksoud AA, Abd El-Ghany IH, El-Beltagi HS, Anankanbil S, Banerijee C, Petersen SV, Guo Z (2018). Adding functionality to milk-based protein: preparation, and physicochemical characterization of $\beta$ lactoglobulinphenolic conjugates. Food Chemistry 241:281-289. https://doi.org10.1016/j.foodchem.2017.08.101

Abdel-Rahim EA, El-Beltagi HS (2010). Constituents of apple, parsley and lentil edible plants and their therapy treatments for blood picture as well as liver and kidney functions against lipidemic disease. Electronic Journal of Environmental, Agricultural and Food Chemistry 9(6):1117-1127. 
Abdulla KA, Um CY, Gross MD, Bostick RM (2018). Circulating $\gamma$-tocopherol concentrations are inversely associated with antioxidant exposures and directly associated with systemic oxidative stress and inflammation in adults. The Journal of Nutrition 148(9):1453-1461. https://doi.org/10.1093/jn/nxy132

Afify AEMM, El-Beltagi HS (2011). Effect of insecticide cyanophos on liver function in adult male rats. Fresenius Environmental Bulletin 20(4a):1084-1088 .

Afify AEMM, El-Beltagi HS,Aly AA, El-Ansary AE (2012). Antioxidant enzyme activities and lipid peroxidation as biomarker for potato tuber stored by two essential oils caraway and clove and its main component carvone and eugenol. Asian Pacific Journal of Tropical Biomedicine 2:S772-S780.

https://doi.org/10.1016/S2221-1691(12)60312-8

Aboul-Enein AM, Shanab SM, Shalaby EA, Zahran MM, Lightfoot DA, El-Shemy HA (2014). Cytotoxic and antioxidant properties of active principals isolated from water hyacinth against four cancer cells lines. BMC Complementary and Alternative Medicine 14:397. https://doi.org/10.1186/1472-6882-14-397

Adewale OB, Egbeyemi KA, Onwuelu JO, Potts-Johnson SS, Anadozie SO, Fadaka AO, ... Onasanya A (2020). Biological synthesis of gold and silver nanoparticles using leaf extracts of Crassocephalum rubens and their comparative in vitro antioxidant activities. Heliyon 6:e05501. https://doi.org/10.1016/j.heliyon.2020.e05501

Ahmeda A, Zangeneh A, Zangeneh MM (2020). Green synthesis and chemical characterization of gold nanoparticle synthesized using Camellia sinensis leaf aqueous extract for the treatment of acute myeloid leukemia in comparison to daunorubicin in a leukemic mouse model. Applied Organometallic Chemistry 34:e5290. https://doi.org/10.1002/aoc.5290

Al Aboody MS (2015). In vitro screening of phytochemical, antibacterial and antioxidant activities of Rumex vesicarius L. International Journal of Current Microbiology and Applied Sciences 4(9):884-893.

Al-Abd AM, Alamoudi AJ, Abdel-Naim AB, Neamatallah TA, Ashour OM (2017). Anti-angiogenic agents for the treatment of solid tumors: potential pathways, therapy and current strategies - a review. Journal of Advanced Research 8(6):591-605. https://doi.org/10.1016/j.jare.2017.06.006

Alberto MR, Canavosio MAR, Nadra MCM (2006). Antimicrobial effect of polyphenols from apple skins on human bacterial pathogens. Electronic Journal of Biotechnology 9:118-125.

https://doi.org/10.2225/vol9-issue3-fulltext-1

Aly AA, Mohamed HI, Mansour MTM, Omar MR (2013). Suppression of powdery mildew on flax by foliar application of essential oils. Journal of Phytopathology 161:376-381. https://doi.org/10.1111/jph.12080

Akladious SA, Mohamed HI (2017). Physiological role of exogenous nitric oxide in improving performance, yield and some biochemical aspects of sunflower plant under zinc stress. Acta Biologica Hungarica 68(1):101-114. https://doi.org/10.1556/018.68.2017.1.9

Amira MA, El-Deeb K, Al-Otibi FO (2011). Assessment of antifungal activity of Rumex vesicarius L. and Ziziphus spinachristi (L.) Willd. extracts against two phytopathogenic fungi. African Journal of Microbiology Research 5(9):1001-1011. https://doi.org/10.5897/AJMR10.826

Ammar NM, Ayoub NA, El-Ahmady SH, Abou El-Kassem LT, Abou Zeid EM (2015). Phytochemical and cytotoxic studies of Rumex pictus Forssk. and Rumex vesicarius L. (Family Polygonaceae), growing in Egypt. European Journal of Medicinal Plants 10(3):1-13. https://doi.org/10.9734/EJMP/2015/19830

Ara I, Bukhari NA, Solaiman, D, Bakir MA (2012). Antimicrobial effect of local medicinal plant extracts in the Kingdom of Saudi Arabia and search for their metabolites by gas chromatography-mass spectrometric (GC-MS) analysis. Journal of Medicinal Plants Research 6(45):5688-5694.

Atteia BMR, El-Kak AE, Lucchesi PA, Delafontane P (2009). Antioxidant activity of folic acid: From mechanism of action to clinical application. Experimental Biology 23(1):103.

Baker, CJ, Mock NM, Roberts DP, Deahl KL, Hapeman CJ, Schmidt WF, Kochansky J (2007). Interference by Mes [2(4-morpholino) ethanesulfonic acid] and related buffers with phenolic oxidation by peroxidase. Free Radical Biology and Medicine 43(9):1322-1327. https://doi.org/10.1016/j.freeradbiomed.2007.07.020

Baskar AA, Al Numair KS, Gabriel Paulraj M, Alsaif MA, Muamar MA, Ignacimuthu S (2012). $\beta$-sitosterol prevents lipid peroxidation and improves antioxidant status and histoarchitecture in rats with 1,2-dimethylhydrazine-induced colon cancer. Journal of Medicinal Food 15(4):335-43. https://doi.org/10.1089/jmf.2011.1780

Begum SMFM, Priya S, Sundararajan R, Hemalatha S (2017). Novel anticancerous compounds from Sargassum wightii: In silico and in vitro approaches to test the antiproliferative efficacy. Journal of Advanced Pharmacy Education \& Research 7(3):272-277. 
Chahardoli A, Karimi N, Sadeghi F, Fattahi A (2018). Green approach for synthesis of gold nanoparticles from Nigella arvensis leaf extract and evaluation of their antibacterial, antioxidant, cytotoxicity and catalytic activities. Artificial Cells, Nanomedicine, and Biotechnology 46(3):579-588. https://doi.org/10.1080/21691401.2017.1332634

Chu W, Lim Y, Radhakrishnan AK, Lim P (2010). Protective effect of aqueous extract from Spirulina platensis against cell death induced by free radicals. BMC Complementary and Alternative Medicine 10:53. https://doi.org/10.1186/1472-6882-10-53

Dawi F, El-Beltagi HS, Abdel-Mobdy YE, Salah SM, Ghaly IS, Abdel-Rahim EA, ... Soliman AM (2021). Synergistic impact of the pomegranate peels and its nanoparticles against the infection of tobacco mosaic virus (TMV). Fresenius Environmental Bulletin 30(1):731-746.

Desai R, Mankad V, Gupta SK, Jha PK (2012). Size distribution of silver nanoparticles: UV-visible spectroscopic assessment. Nanoscience and Nanotechnology Letters 4:30-34. https://doi.org/10.1166/nnl.2012.1278

El-Beltagi HES (2011). Effect of roasting treatments on protein fraction profiles, some enzyme activities of Egyptian peanuts. International Journal of Food Sciences and Nutrition 62(5):453-456.

El-Beltagi HS, Ahmed SH, Namich AAM, Abdel-Sattar RR (2017) Effect of salicylic acid and potassium citrate on cotton plant under salt stress. Fresenius Environmental Bulletin 26(1a):1091-1100

El-Beltagi HS, Mohamed HI, Safwat G, Megahed BMH, Gamal M (2018) Evaluation of some chemical constituents, antioxidant, antibacterial and anticancer activities of Beta vulgaris L. root. Fresenius Environmental Bulletin 27(9):6369-6378.

El-Beltagi HS, Mohamed HI, Elmelegy AA, Eldesoky SE, Safwat G (2019a). Phytochemical screening, antimicrobial, antioxidant, anticancer activities and nutritional values of cactus (Opuntia Ficus Indicia) pulp and peel. Fresenius Environmental Bulletin 28(2A):1534-1551.

El-Beltagi HS, Mohamed HI, Safwat G, Gamal M, Megahed BMH (2019b). Chemical composition and biological activity of Physalis peruviana L. Gesunde Pflanzen 71:113-122. https://doi.org/10.1007/s10343-019-00456-8

El-Beltagi HS, Mohamed HI, Sofy MR (2020a) Role of ascorbic acid, glutathione and proline applied as singly or in sequence combination in improving chickpea plant through physiological change and antioxidant defense under different levels of irrigation intervals. Molecules 25:1702. https://doi.org/10.3390/molecules25071702

El-Beltagi HS, Sofy MR, Aldaej MI, Mohamed HI (2020b) Silicon alleviates copper toxicity in flax plants by up-regulating antioxidant defense and secondary metabolites and decreasing oxidative damage. Sustainability 12:4732. https://doi.org/10.3390/su12114732

El-fayoumy EA, Shanab SM, Gaballa HS, Tantawy MA, Shalaby EA (2021). Evaluation of antioxidant and anticancer activity of crude extracts and different fractions of Chlorella vulgaris axenic culture grown under various concentrations of copper ions. BMC Complementary Medicine and Therapies 21:1-16. https://doi.org/10.1186/s12906-020-03194-X

Farooq M, Abutaha N, Mahboob M, Baabbad N, Almoutiri ND, Wadaan MAAM (2020). Investigating the antiangiogenic potential of Rumex vesicarius (humeidh), anticancer activity in cancer cell lines and assessment of developmental toxicity in zebrafish embryos. Saudi Journal of Biological Sciences 27:611-622. https://doi.org/10.1016/j.sjbs.2019.11.042

Gaber NB, El-Dahy SI, Shalaby EA (2021). Comparison of ABTS, DPPH, permanganate, and methylene blue assays for determining antioxidant potential of successive extracts from pomegranate and guava residues. Biomass Conversion and Biorefinery. https://doi.org/10.1007/s13399-021-01386-0.

Gandhi, MSA, Kumar VS, Li Q (2020). Synthesis of silver nanoparticles using Rumex crispus extract and evaluation of their antibacterial activities. Asia Communications and Photonics Conference 2020, paper M4A.5 https://doi.org/10.1364/ACPC.2020.M4A.5

Harborne JB (1973). Phytochemical methods: A guide to modern technique of plant analysis. Chapmann and Hall, London, pp 271-279.

Hariprasad P, Ramakrishnan N (2011). Phytochemical screening and pharmacognostical evaluation of Rumex vesicarius L. International Journal of Pharma Tech Research 3(2):1078-1082.

Hariprasad PS, Ramakrishnan N (2011). GC-MS analysis of Rumex vesicarius L. International Journal of Drug Development \& Research 3(2):272-279.

Huo Y, Singh P, Kim YJ, Soshnikova V, Kang J, Markus J, ... Yang DC (2018). Biological synthesis of gold and silver chloride nanoparticles by Glycyrrhiza uralensis and in vitro applications. Artificial Cells, Nanomedicine, and Biotechnology 46(2):303-312. https://doi.org/10.1080/21691401.2017.1307213 
Huyut Z, Beydemir Ş, Gülçin İ (2017). Antioxidant and antiradical properties of selected flavonoids and phenolic compounds. Biochemistry Research International 2017:7616791. https://doi.org/10.1155/2017/7616791

Ilya E, Kulikova L, Van der Eycken EV, Voskressensky L (2018). Recent advances in phthalan and coumaran chemistry. Chemistry Open 7(11):914-929. https://doi:10.1002/open.201800184.

Imran M, Raja MM, Basith JA (2011). Determination of total phenol, flavonoid and antioxidant activity of edible mushrooms Pleurotus florida and Pleurotus eous. International Food Research 18:574-577.

Jin X, Simeon NC, Palma J, Kim D, Ngabire D, Kim N-H, ... Kim G-D (2018). Anticancer activity of Sasa borealis leaf extract-mediated gold nanoparticles AU -Patil, Maheshkumar Prakash. Artificial Cells, Nanomedicine, and Biotechnology 46(1):82-88.

Kaviarasan S, Naik GH, Gangabhagirathi R, Anuradha CV, Priyadarsini KI (2007). In vitro studies on antiradical and antioxidant activities of fenugreek (Trigonella foeveem) seeds. Food Chemistry 103:31-37. https://doi.org/10.1016/j.foodchem.2006.05.064

Khan TH, Ganaie MA, Siddiqui AN, Alam, A, Ansari NM (2014). Antioxidant potential of Rumex vesicarius L.: in vitro approach. Asian Pacific Journal of Tropical Biomedicine 4(7):538-544. https://doi.org/10.12980/APJTB.4.2014C1168

Khan S, Richa, Kaur H, Jhamta R (2019). Evaluation of antioxidant potential and phytochemical characterization using GCMS analysis of bioactive compounds of Achillea filipendulina (L.) leaves. Journal of Pharmacognosy and Phytochemistry 8(3):258-265.

Khattak U, Ullah R, Khan S, Afriq S, Rauf A, Hassanien M (2019). Synthesis, characteristics and biological activities of silver nanoparticles from Euphorbia dracunculoides. EurAsian Journal of BioSciences 13(2):2249-2260.

Lakshmanan G, Sathiyaseelan A, Kalaichelvan PT, Murugesan K (2018). Plant-mediated synthesis of silver nanoparticles using fruit extract of Cleome viscosa L.: assessment of their antibacterial and anticancer activity. Karbala International Journal of Modern Science 4(1):61-68. https://doi.org/10.1016/j.kijoms.2017.10.007

Melichacova S, Timoracka M, Bystrick J, Vollmannova A, Cery I (2010). Relation of total antiradical activity and total polyphenol content of sweet cherries (Prunus avium L.) and tart cherries (Prunus cerasus L.). Acta Agriculturae Slovenica 95(1):21-28. https://doi.org/10.2478/v10014-010-0003-3

Nair R, Kalariya T, Chanda S (2005). Antibacterial activity of some selected Indian medicinal flora. Turkish Journal of Biology 29:41-47.

Ndikau M, Noah NM, Andala DM, Masika E (2017). Green synthesis and characterization of silver nanoparticles using Citrullus lanatus fruit rind extract. International Journal of Analytical Chemistry 8108504. https://doi.org/10.1155/2017/8108504.

Mohamed AA, El-Beltagi HS, Rashed MM (2009). Cadmium stress induced change in some hydrolytic enzymes, free radical formation and ultrastructural disorders in radish plant. Electronic Journal of Environmental, Agricultural and Food Chemistry 8(10):969-983.

Mohamed HI, El-Beltagi HS, Aly AA, Latif HH (2018a). The role of systemic and non systemic fungicides on the physiological and biochemical parameters in Gossypium hirsutum plant, implications for defense responses. Fresenius Environmental Bulletin 27(12):8585-8593.

Mohamed HI, Akladious SA, El-Beltagi HS (2018b). Mitigation the harmful effect of salt stress on physiological, biochemical and anatomical traits by foliar spray with trehalose on wheat cultivars. Fresenius Environmental Bulletin 27(10):7054-7065.

Nivas D, Gaikwad DK, Havan PD (2010). Antiradical activity of radically important Morinda pubescens fruits. International Journal of Pharma and Bio Sciences 1(3):1-4.

Panduraju T, Rao RS, Kumar SV (2009). A study on antimicrobial activity of Rumex vesicarius L. International Journal of Pharmacy and Technology 1:21-25.

Panja S, Choudhuri I, Khanra K, Pati B, Bhattacharyya N (2020). Biological and Photocatalytic activity of silver nanoparticle synthesized from Ehretia laevis Roxb. leaves extract. Nano Biomedicine and Engineering 12(1):104-113.

Prema R, Sekar DSS, Sekhar KBC, Jeevanandham S (2012). In vitro cytotoxicity study on combined plants extracts (Cissus quadrangularis and Aegle marmelos). European Journal of Experimental Biology 2:882-888.

Rao BN (2003). Bioactive phytochemicals in Indian foods and their potential in health promotion and disease prevention. Asia Pacific Journal of Clinical Nutrition 12:9-22. 
Re R, Pellegrini RN, Proteggente A, Pannala A, Yang M, Rice- Evans C (1999). Antioxidant activity applying improved ABTS radical cation decolorization assay. Free Radical Biology and Medicinal 26:1231-1237. https://doi.org/10.1016/s0891-5849(98)00315-3

Rossenthaler L (1930). The chemical investigation of plants. Translated into English by Sudhamoy Ghosh from the Third German edition. Bell and Sons. Ltd London.

Salari S, Esmaeilzadeh Bahabadi S, Samzadeh-Kermani A, Yosefzaei F (2019). In-vitro evaluation of antioxidant and antibacterial potential of greensynthesized silver nanoparticles using Prosopis farcta fruit extract. Iranian Journal of Pharmaceutical Research 18(1):430-455.

Sayik A, Serguzel A, Yusufoglu AS, Acik L, Turker G, Aydin B, Arslan L (2017). DNA- binding, biological activities, and chemical composition of wild growing Epilobium angustifolium L. extracts from Canakkale, Turkey. Journal of Turkish Chemical Society 4(3):811-840.

Shalaby EA, Shanab SMM (2013). Comparison ofDPPH and ABTS assays for determining antioxidant potential of water and methanol extracts of Spirulina platensis. Indian Journal of Geo-Marine Sciences 42(5):556-564.

Shallan MA, El-Beltagi HS, Mona AM, Amera TM, Sohir NA (2010). Effect of amylose content and pre-germinated brown rice on serum blood glucose and lipids in experimental animal. Australian Journal of Basic and Applied Scieces 4(2):114-121.

Shanab SM, Mostafa SS, Shalaby EA, Mahmoud GI (2012). Aqueous extracts of microalgae exhibit antioxidant and anticancer activities. Asian Pacific Journal of Tropical Medicine 2:608-615. https://doi.org/10.1016/S22211691(12)60106-3

Sheela D, Uthayakumaria F (2013). GC-MS analysis of bioactive constituents from coastal sand dune taxone-Sesuivum portulacastrum. Bioscience Discovery 4(1):47-53.

Sroka Z (2006). The screening analysis of antiradical activity of some plant extracts. Postepy Higieny i Medycyny Doswiadczalnej 60: 563-570.

Stevic T, Savikin K, Ristic M, Zdunic G, Jan kovic T, Krivokuca D, Vulic T (2010). Composition and antimicrobial activity of the essential oil of the leaves of black currant (Ribes nigrum L.) cultivar Cacanska crna. Journal of Serbian Chemical Society 75(1):35-43. https://doi.org/10.2298/JSC1001035S

Sudha A, Jeyakanthan J, Srinivasan P (2017). Green synthesis of silver nanoparticles using Lippia nodiflora aerial extract and evaluation of their antioxidant, antibacterial and cytotoxic effects. Resource-Efficient Technologies 3(4):506-515. https://doi.org/10.1016/j.reffit.2017.07.002

Tirzitis G, Bartosz G (2010). Determination of antiradical and antioxidant activity: basic principles and new insights, Acta Biochemica Polonica 75(1):139-142.

Trease GE, Evans WC (1983). The text book of pharmacognosy. (12th Edn.,) Balliere, Tindall, London, pp 57-59.

Vanaja M, Shanmugam R, Paulkumar K, Gnanajobitha G (2013). Kinetic study on green synthesis of silver nanoparticles using Coleus aromaticus leaf extract. Advances in Applied Science Research 4(3):50-55.

Wang J, Liu H, Zhao J, Gao H, Zhou L, Liu Z, Chen Y, Sui P (2010). Antimicrobial and antioxidant activities of the root bark essential oil of Periploca sepium and its main component 2-hydroxy-4-methoxybenzaldehyde. Molecules 15(8):5807-5817. https://doi.org/10.3390/molecules15085807

Wen XB, Miao F, Zhou L, Zhang M, He QL (2012). In vitro antioxidant activity of Parnassia wightiana W. extracts. Chinese Journal of Natural Medicines 10(3):190-195. https://doi.org/10.3724/SP.J.1009.2012.00190

Wondrak GT, Cabello CM, Villeneuve NF, Zhang S, Ley Y, Li S, ... Zhang DD (2008). Cinnamoyl-based Nrf2-activators targeting human skin cell photo-oxidative stress. Free Radical Biology and Medicine 45(4):385-395. https://doi.org/10.1016/j.freeradbiomed.2008.04.023

Yen GC, Chen HY (1995). Antioxidant activity of various tea extracts in relation to their anti-mutagenicity. Journal of Agriculture and Food Chemistry 43:27-37. https://doi.org/10.1021/jf00049a007

Yousaf H, Mehmood A, Ahmed KS, Raffi M (2020). Green synthesis of silver nanoparticles and their applications as an alternative antibacterial and antioxidant agent. Materials Science and Engineering: C 112:110901. https://doi.org/10.1016/j.msec.2020.110901

Yugaya YA, Usoltsevab RV, Silantevc VE, Egorovaad AE, Karabtsove AA, KumeikodfVV, ... Shkryl YN (2020). Synthesis of bioactive silver nanoparticles using alginate, fucoidan and laminaran from brown algae as a reducing and stabilizing agent. Carbohydrate Polymers 245:116547. https://doi.org/10.1016/j.carbpol.2020.116547

Zabot GP, Carvalhal GF, Marroni NP, Licks F, Hartmann RM, da Silva VD, Fillmann HS. (2017). Glutamine prevents oxidative stress in a model of portal hypertension. World Journal of Gastroenterology 23(25):4529-4537. https://doi.org/10.3748/wjg.v23.i25.4529 
The journal offers free, immediate, and unrestricted access to peer-reviewed research and scholarly work. Users are allowed to read, download, copy, distribute, print, search, or link to the full texts of the articles, or use them for any other lawful purpose, without asking prior permission from the publisher or the author.

(c) (9)

License - Articles published in Notulae Botanicae Horti Agrobotanici Cluj-Napoca are Open-Access, distributed under the terms and conditions of the Creative Commons Attribution (CC BY 4.0) License. (C) Articles by the authors; UASVM, Cluj-Napoca, Romania. The journal allows the author(s) to hold the copyright/to retain publishing rights without restriction. 